Review

\title{
Seismic and Thermal Retrofitting of Masonry Buildings with Fiber Reinforced Composite Systems: A State of the Art Review
}

\author{
${ }^{1}$ Arnas Majumder, ${ }^{2 *}$ Flavio Stochino, ${ }^{1}$ Fernando Fraternali and ${ }^{1}$ Enzo Martinelli \\ ${ }^{1}$ Department of Civil Engineering, University of Salerno, Via Giovanni Paolo II, 132, 84084 Fisciano (SA), Italy \\ ${ }^{2}$ Department of Civil Environmental Engineering and Architecture, University of Cagliari, \\ via Marengo 2, 09123 Cagliari, Italy
}

Article history

Received: 08-12-2020

Revised: 19-02-2021

Accepted: 22-02-2021

Corresponding Author:

Flavio Stochino

Department of Civil

Environmental Engineering and

Architecture, University of

Cagliari, via Marengo 2, 09123

Cagliari, Italy

Email: fstochino@unica.it

\begin{abstract}
Old masonry buildings represent the largest part of traditional constructions. Generally, they are both seismically vulnerable and thermally dispersive. Therefore, the need for seismic and thermal retrofitting aimed at reducing their vulnerability and environmental impact has motivated research efforts towards sustainable retrofitting solutions. This study presents a literature review of the approaches currently available for masonry retrofitting. Specifically, it highlights the use of fiber in textile form i.e., Textile Reinforcement Mortar (TRM), as Fiber Reinforced Polymer (FRP) and natural fibers (animal and plant sources) to masonry retrofitting. In addition, specific attention is devoted to the integrated (structural and thermal) fiber-based integrated retrofitting techniques that are becoming very important in the last years.
\end{abstract}

Keywords: Masonry, Fiber Reinforcement, Integrated Retrofitting

\section{Introduction}

The largest part of the European traditional built stock consists of masonry buildings and most of these did not comply with the current standards for seismic safety and thermal efficiency. Specifically, in Italy, there are about 7 million masonry buildings (Pittau et al., 2017). Furthermore, according to the Italian Istitute of Statistics (Formisano et al., 2019) around 57\% of the total residential buildings are masonry buildings. In addition, about $90 \%$ of these are constructed before nineties (Mistretta et al., 2019).

Based on the data provided by the European Commission (EC, 2019a), approximately $75 \%$ of the building realized more than 50 years ago is thermal inefficient. In addition, according to (Martelli, 2013; Basu et al., 2014), about $70 \%$ of existing buildings are seismically vulnerable in Italy. Therefore, considering the preceding two paragraphs it is patent that a huge part of the masonry buildings needs structural and thermal retrofitting.

The nature and the environment around us are hugely affected and influenced by the existing building stock, in terms of energy consumptions and $\mathrm{CO}_{2}$ emissions. Indeed, this sector consumes around $36 \%$ of the world total energy and release $39 \%$ of the total carbon dioxide (Benzar et al., 2020). With specific reference to Europe, the percentages are about 40 and 36\% (EC, 2019b), respectively. In addition, in Europe about $50 \%$ of the total energy consumption is used for heating and cooling as reported in (Pohoryles et al., 2020). In order to enhance the energy performance of buildings, a legislative framework has been established by the EU, which includes the Energy Performance of Buildings Directive (EPBD) (2010/31/EU) as in (EP, C.E.U. 2010) and the energy efficiency directive (2012/27/EU) (EP, C.E.U. 2012) Furthermore, both these directives are amended by the directive on Energy Performance of Buildings (2018/844/EU) (EP, C.E.U. 2018). In fact, the push for the thermal performance retrofitting came with the EPBD.

Given the growing awareness about the environmental impact of buildings, sustainable energy management is being a part of the conservation strategy of the historical and heritage buildings and a part of the design of the new constructions. Indeed, it can help improve the thermal energy efficiency and comfort as expressed by (De Santoli and Ambrosio, 2014). Thus, in order to obtain the refurbishment, preservation and restoration of historical and heritage buildings, it is also important to use sustainable and ecofriendly materials.

The durability of structures and the comfort of their occupants depend on material characteristics and internal 
thermo-hygrometric ambient conditions as described in (Dell'Isola et al., 2012).

The growing social awareness of building environmental impact (Paris Agreement UNFCCC, 2015), the targeted sustainable goals according to (UN.SDG, 2020), the improvement of the seismic performance required by (EN, 1998) (Eurocode 8) and the energy performance standards like (EN ISO 52016-1, 2017) have led the engineers to look for integrated retrofitting methods and sustainable materials which can be used for both thermal and seismic retrofitting (EU framework 2010/31/EU and 2018/844/EU). In this context a key role can be played by fibers and integrated retrofitting techniques.

This study presents a state-of-the-art review of techniques for integrated retrofitting of masonry buildings, with emphasis on those based on the use of fiber-reinforced composite systems.

\section{Fiber Classifications and use of Fiber Reinforced Composites for Masonry Retrofitting}

Composite systems are based on two main "phases": Fibers and mortar. The former can be grouped into natural and man-made fibers. In general, they are used in the form of either raw fibers or fabrics. Raw fibers are cut or chopped at various sizes, whereas the textile fibers are used in mesh form and can be obtained by using one or more kinds of fiber. Figure 1 proposes a comprehensive classification of fibers. Man-made fibers, obtained from materials like metals, carbon and glass, present good structural performances. These fibers can be applied in various composite systems and are expressed in the sections-Textile Reinforced Mortar (TRM) and Fiber-Reinforced Polymer (FRP).

Recently, the use of natural fibers, derived from both plants and animals, is becoming a new trend for sustainable retrofitting of buildings. For instance, sheep wool represents an effective animal fiber for retrofitting (Valenza et al., 2015).

Different varieties of plant fibers have been used for the same purpose in the last years: Raw hemp fiber (Formisano et al., 2017), hemp fiber mesh (Menna et al., 2015), flax fibers and fabrics (Ferrara et al., 2020), jute (Formisano et al., 2019), palm oil fiber (Raut and Gomez, 2016), date palm fiber (Benmansour et al., 2014), banana leaves, reed, palm tree leaves and coconut seeds (Al-Zubaidi, 2018).

As highlighted in (Bambach, 2020), some of the natural and man-made fibers have been compared in terms of stress-strain relation: The former (jute, hemp and flax) have nonlinear stress-strain response, while the latter (carbon and glass) mainly behave linearly (Fig. 2).

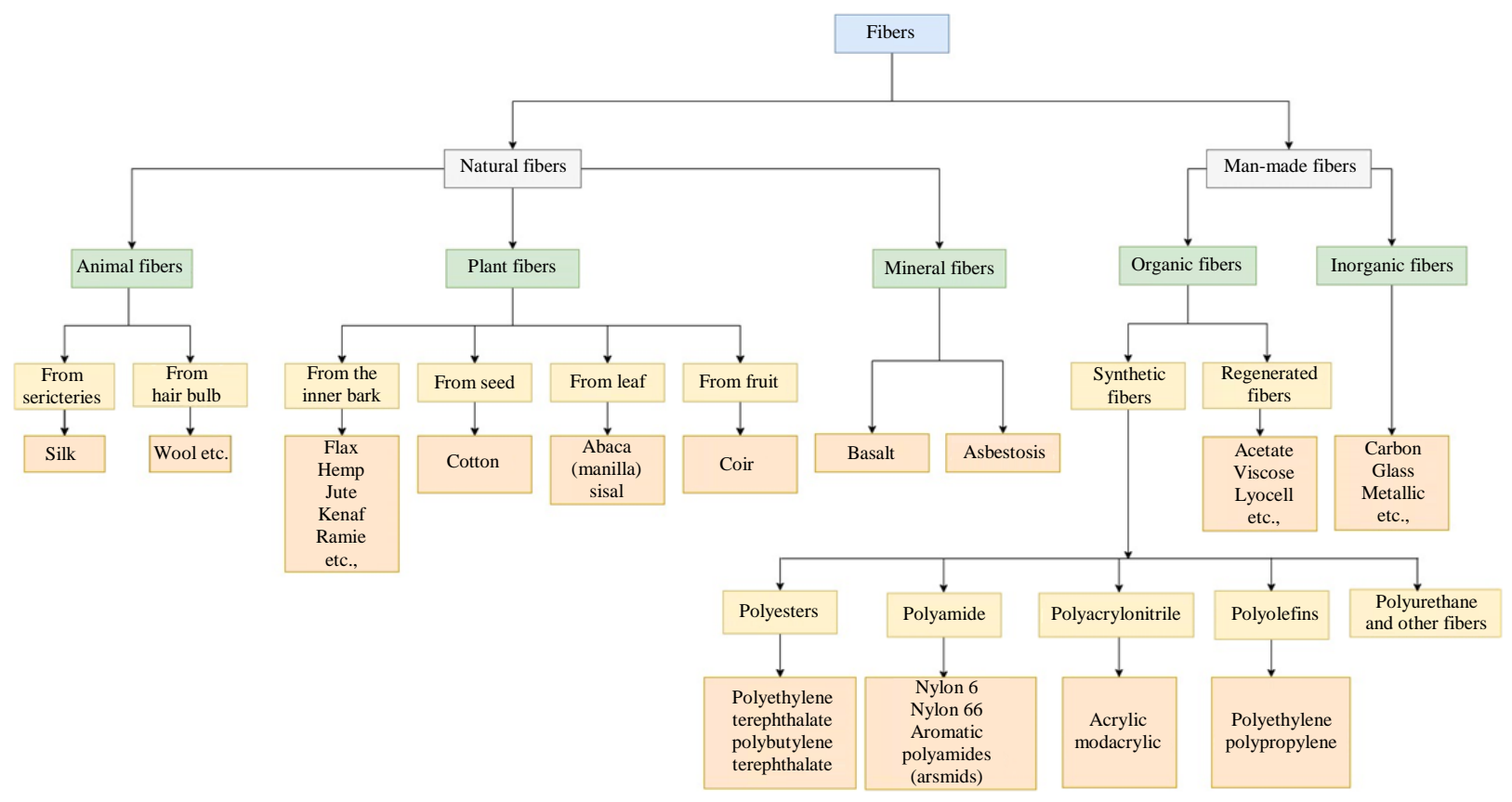

Fig. 1: Classification of fibers, elaborated from (Amaral et al., 2018; Deopura and Padaki, 2015; Barbosa et al., 2004; Saba et al., 2014; Saleem et al., 2020) 


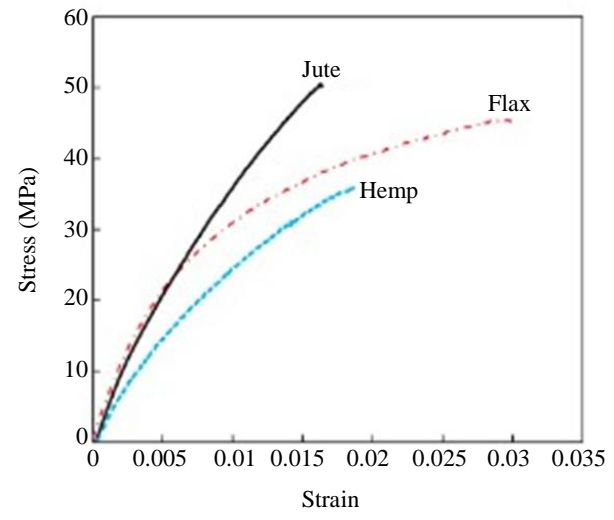

(a)

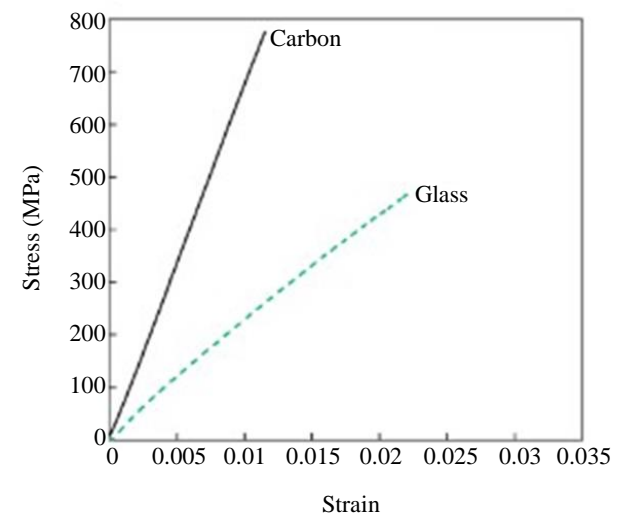

(b)

Fig. 2: (a) Natural and (b) man-made fibers composite laminate (Bambach, 2020)

\section{Classification of Masonry Retrofitting Techniques}

Structural retrofitting is aimed at protecting masonry buildings from external loads and, in particular, from seismic actions. The choice of strengthening method and strategies (improving ductility or strength) might depend on the building location and characteristics and on the available budget (Fig. 3).

It is possible to classify masonry retrofitting according to the following criteria:

i) Techniques used for retrofitting (See the sectionMasonry Retrofitting Techniques)

ii) Type of fibers (see the section-Fibers used for Masonry Retrofitting)

iii) Purpose of the retrofitting: Structural or thermal performance improvement (see the sectionMasonry Retrofitting: Structural and Thermal Performance Improvement)

\section{Masonry Retrofitting Techniques}

\section{Reinforced Plaster}

Plaster is a composite material where clay, cement, lime, gypsum etc. are mixed with water, sand or other reinforcing materials like fibers.

Plaster is used for both structural and thermal retrofitting of masonry. Traditionally, plaster is enriched with steel bar and a thin layer (Elgawady et al., 2004). New type of structural/mechanical and thermal retrofitting plastering materials have been developed in the last years. Basaran et al. (2013) have prepared two types of reinforcing plasters using sand, Portland cement and fibers. Polypropylene and the steel fibers have been used as additives for masonry structural reinforcement.

Very interestingly, have developed olive-fiber based clayey-plaster with improved insulating capacity. It is a bio-based plaster prepared with clay, sand and olive pruning waste fibers (leaves and branches). Aizi and
Kaid-Harche (2020) used gypsum and natural fiber retama monosperma to create composite plaster reinforcement material, Fig. 4.

Furthermore, (Mustafaraj et al., 2020) have used polypropylene fiber for the reinforcement purpose in masonry, Fig. 5.

\section{Ferrocement}

Ferrocement is a mixture of cement mortar and reinforcement elements, without any coarse aggregate (Sakthivel and Jagannathan, 2011). Figure 6 for typical ferrocement retrofitting scheme, (Wang et al., 2018).

Ferrocement is commonly used in the construction sector (Nedwell and Swamy, 1994). It has been found that when it is put on the structure surfaces, it can significantly enhance both the in-plane and out-of-plane capacity (Lizundia et al. 1997), as well as lateral load capacity (Ashraf et al., 2012; Ali Shah et al., 2017).

\section{Shotcrete Sprayed}

Shotcrete is a technique in which concrete, or mortar, is directly sprayed on the structure to enhance its strength capacity (Warnar, 1996). In addition, it helps dissipate seismic energy, as stated by (Shabdin et al., 2018). A good example for masonry application of shotcrete is reported by (Elgawady et al., 2006) that have retrofitted both sides of a masonry wall using shotcrete process as presented in Fig. 7.

Banthia (2019) reports that there are primarily two processes that can be used for shotcrete retrofitting: The wet-process and the dry-process. In the former case, shotcrete is ready to use as a concrete mixture, while in the latter case the water is added separately along with the bone-dry cementitious mixture.

Shotcrete reinforcements usually are mesh and bars (Shabdin et al., 2018). Actually, also filler or binding materials like hemp fibers (Yun et al., 2019) and SilicaFume (Army, 1993) can be used in the shotcrete spraying mixture.

The application of shotcrete in masonry, has been mention in (Wang et al., 2018) and Fig. 7. 
Arnas Majumder et al. / International Journal of Structural Glass and Advanced Materials Research 2021, Volume 5: 41.67 DOI: 10.3844/sgamrsp.2021.41.67

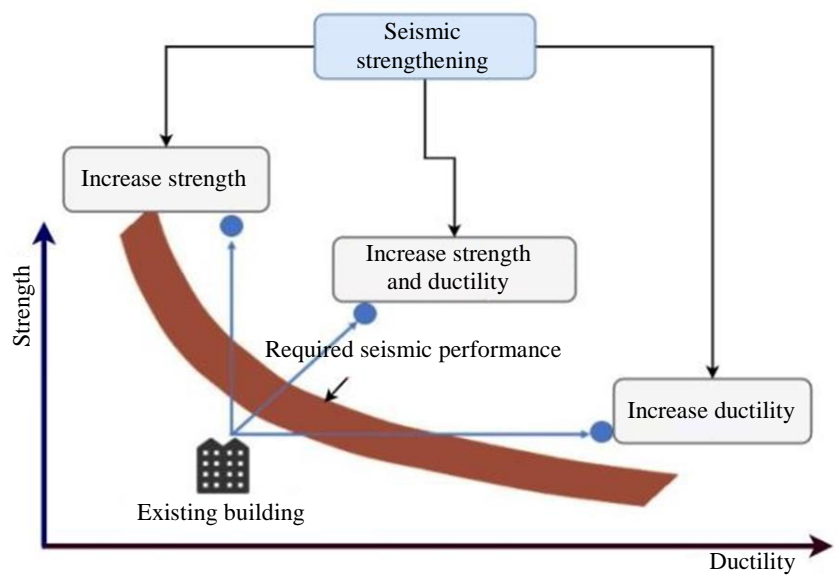

Fig. 3: Strategies for seismic retrofitting (Ferretti, 2019)

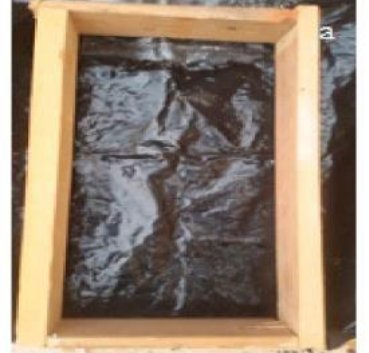

(a)

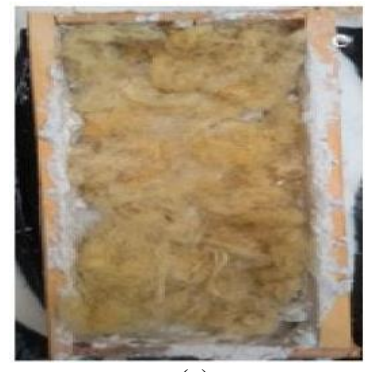

(c)

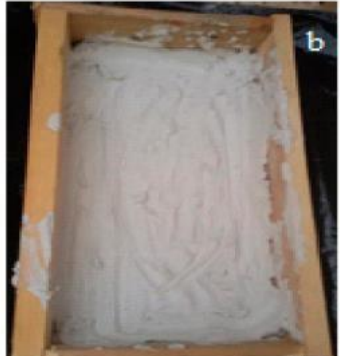

(b)

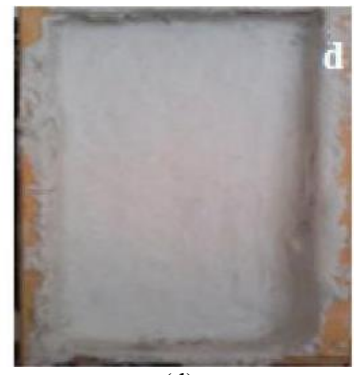

(d)

Fig. 4: Preparation of composite plaster (Aizi and Kaid-Harche, 2020)

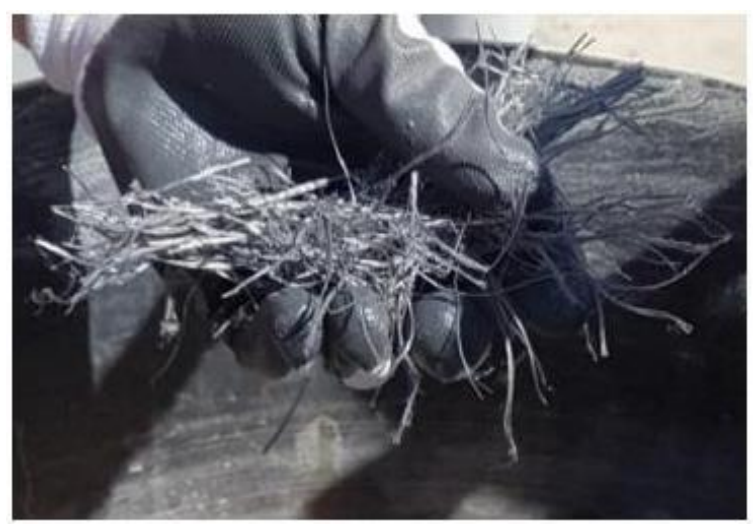

Fig. 5: Polypropylene fiber (Mustafaraj et al., 2020)

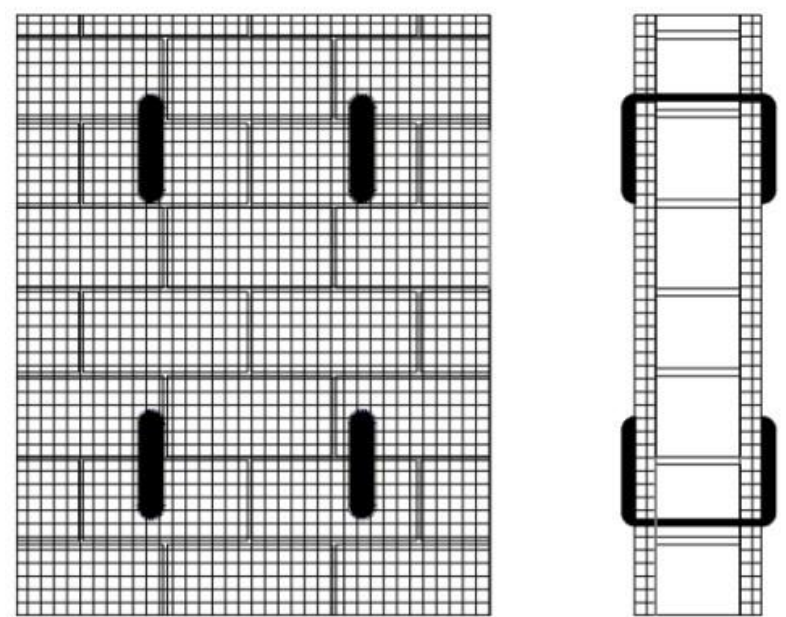

Fig. 6: Ferrocement retrofitting scheme (Wang et al., 2018)

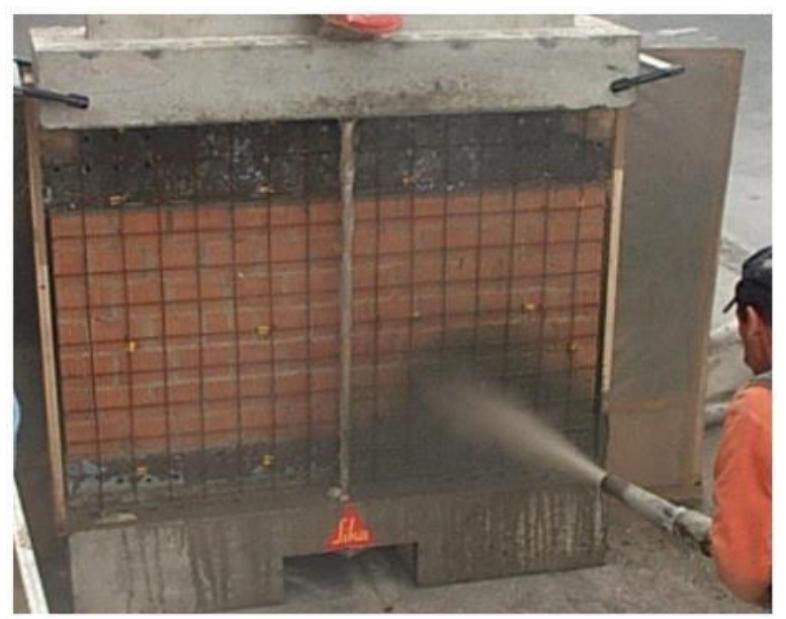

Fig. 7: Shotcrete spraying process (Wang et al., 2018) 


\section{Application of Fiber Net}

A quite common approach for masonry retrofitting is the application of a reinforcing net on the external wall surfaces. This net can be obtained using FRP or directly open fabric made of various kinds of fiber rovings, as cited in (Oskouei et al., 2018).

Mustafaraj et al. (2020) have used polypropylene net for masonry panels reinforcement, Fig. 8.

\section{Grout and Epoxy Injection}

Grouting is a process where any filler materials is injected into the structural element that needs retrofitting. The injecting materials mainly used are cement (Vintzileou and Tassios, 1995) and lime-based mortar (Almeida et al., 2012).

As stated by (Isfeld et al., 2016), through this process the masonry walls can be retrofitted and restored, keeping originality of the wall and improving the structural performance.

Vintzileou et al. (2015) have used the process of grouting to retrofit a masonry building with natural hydraulic lime-based grout, after a seismic excitation in an experimental test. In (Christou and Elliotis, 2016) (Fig. 9), demonstrated the installment of the grout through rubber tubes in the wall.

\section{The Insertion of a Reinforced Concrete $(R C)$}

As reported in (Mistretta et al., 2019), improvement in seismic energy dissipation capacity and ductility of the structure can be also achieved through Reinforced Concrete $(\mathrm{RC})$ frames insertion.

\section{Horizontal Connectors (Diatons)}

Horizontal connectors, also known as transversal connectors or diatons, are structural elements inserted orthogonally into the masonry wall to connect its two external surfaces and to strongly improve its shear resistance. Traditionally, various types of horizontal connectors made of timber, bamboo, reed and stones have been used all around the world as highlighted by (Ortega et al., 2017).

For modern masonry buildings, more advanced transversal reinforcement elements or diatons are also used (Mistretta et al., 2019) (Figs. 10 and 11). They are made of two plastic anchoring parts that hold a fiber mesh or a combination of stainless-steel micro cords and plastic mesh. In addition, a specific mortar is injected inside the mesh in order to create a real reinforced mortar transversal beam.

Mustafaraj et al. (2020) have created the transversal connectors with by wrapping the fiberglass around the GFRP bar, as in Fig. 12.

Generally, these horizontal connectors improve the out-of-plane bending and in-plane shear resistance (Siddiqui et al., 1996). In case of the application of a fiber net reinforcement (for example FRP, TRM), this type of connector as in is very important because it influence the stability of the wall and helps to grip the fiber mesh on the two external sides.

\section{Reinforced Mortar (RM) with Metallic Cross Strips}

Dong et al. (2019) have retrofitted Un-Reinforced Masonry (URM) walls with mortar and cross steel bars that are placed diagonally (Fig. 13). Single and double-faced URM walls were strengthened and tested applying low-cyclic load keeping the vertical load constant. The improvement in shear capacity is around $38.2 \%$.

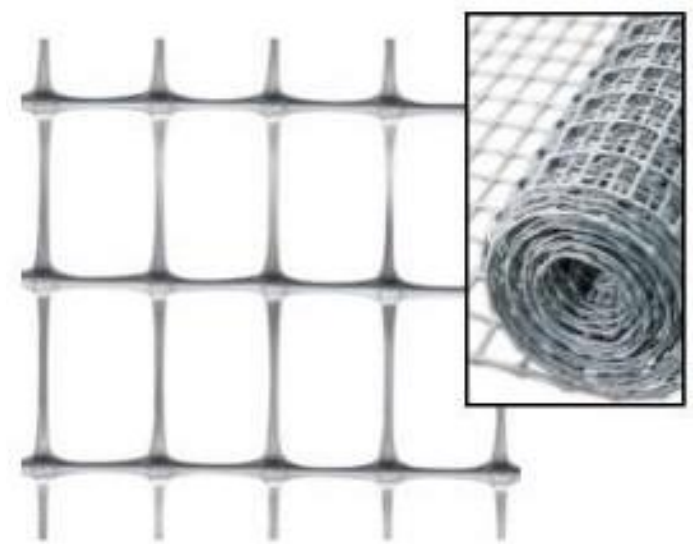

Fig. 8: Polypropylene net (Mustafaraj et al., 2020)

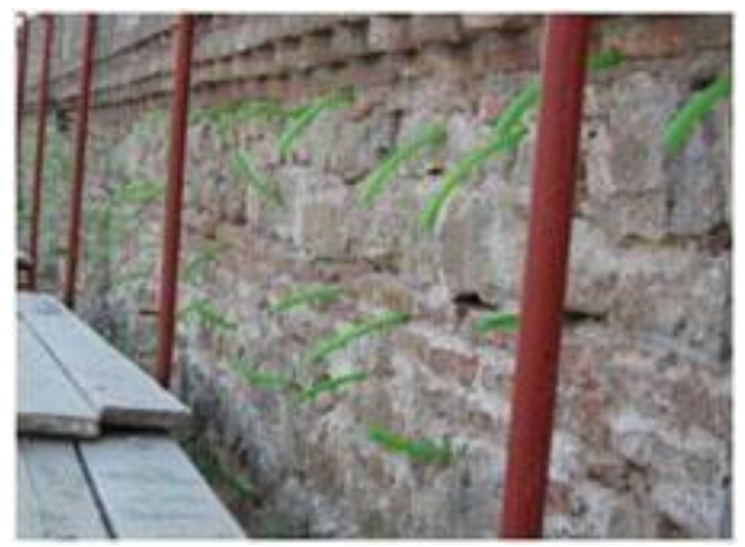

Fig. 9: Grouting-the installment of the grout through rubber tubes in the wall (Christou and Elliotis, 2016)

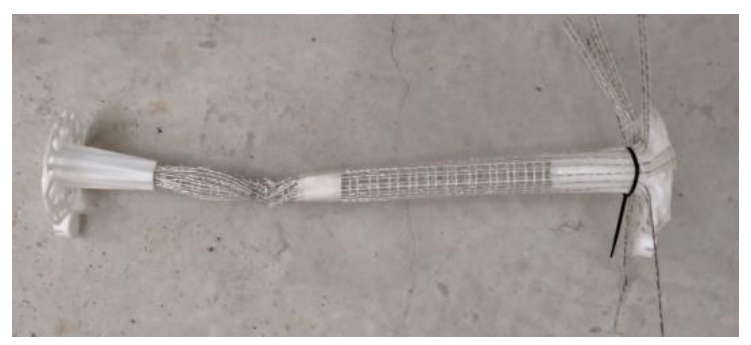

Fig. 10: Transversal diaton 
Arnas Majumder et al. / International Journal of Structural Glass and Advanced Materials Research 2021, Volume 5: 41.67 DOI: 10.3844/sgamrsp.2021.41.67

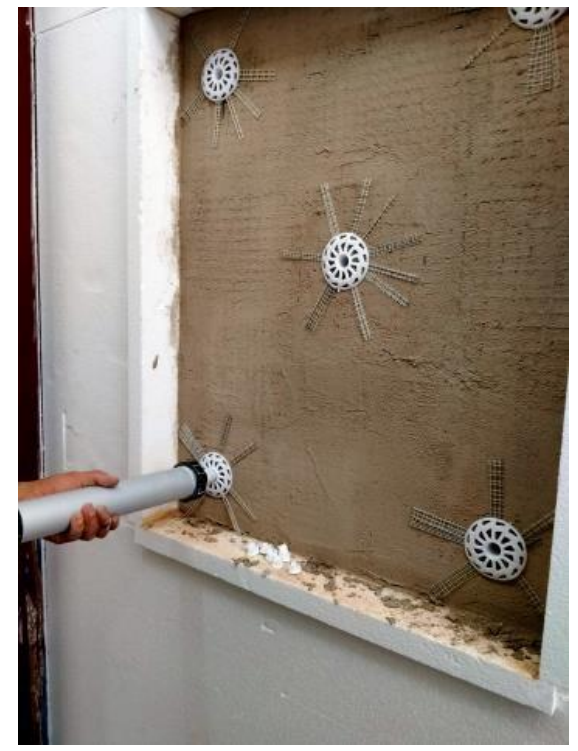

Fig. 11: Mortar injection in the diatons cavity

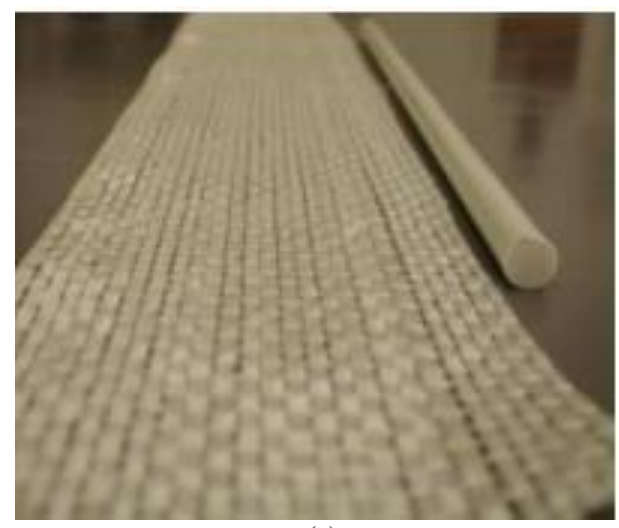

(a)

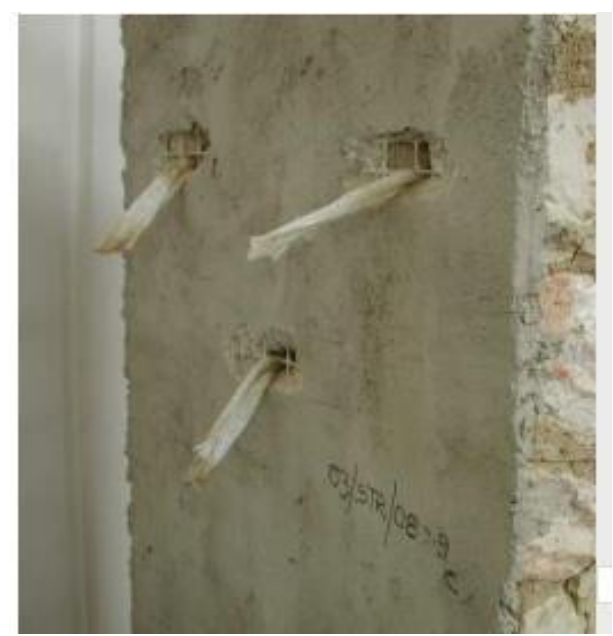

(b)

Fig. 12: GFRP bar and fiberglass sheet wrapped to use as horizontal connector (Mustafaraj et al., 2020)

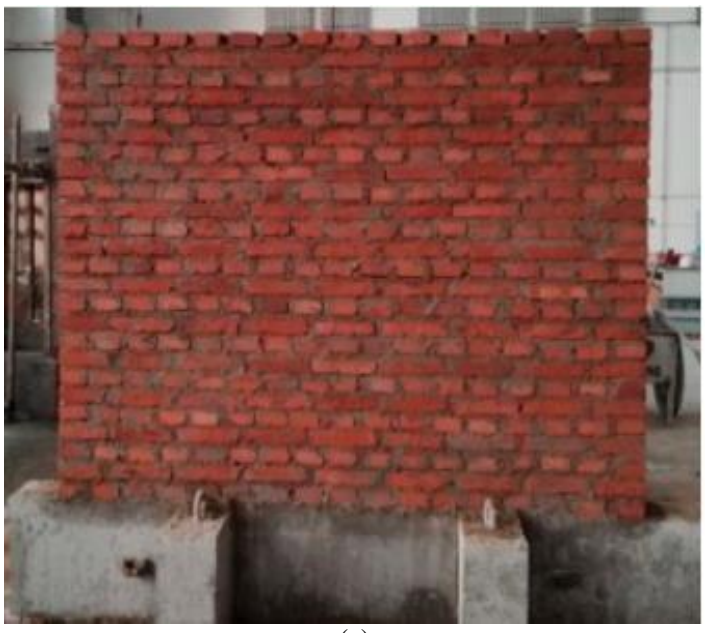

(a)

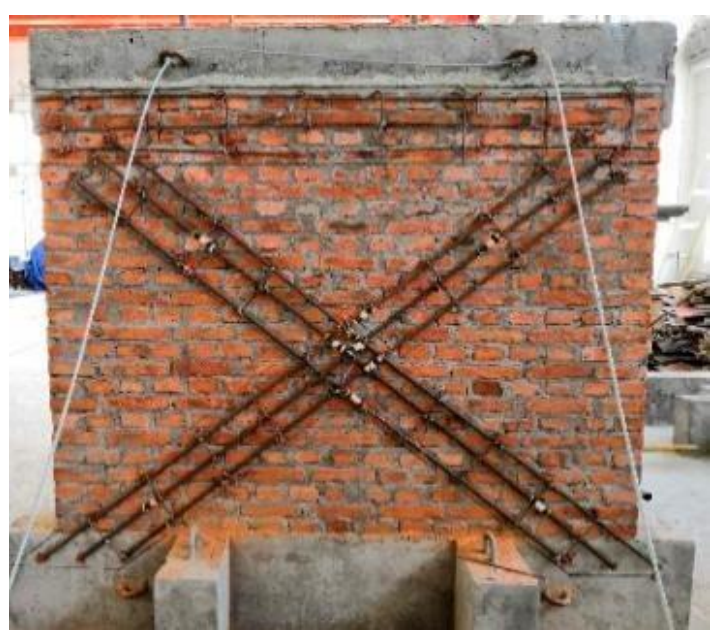

(b)

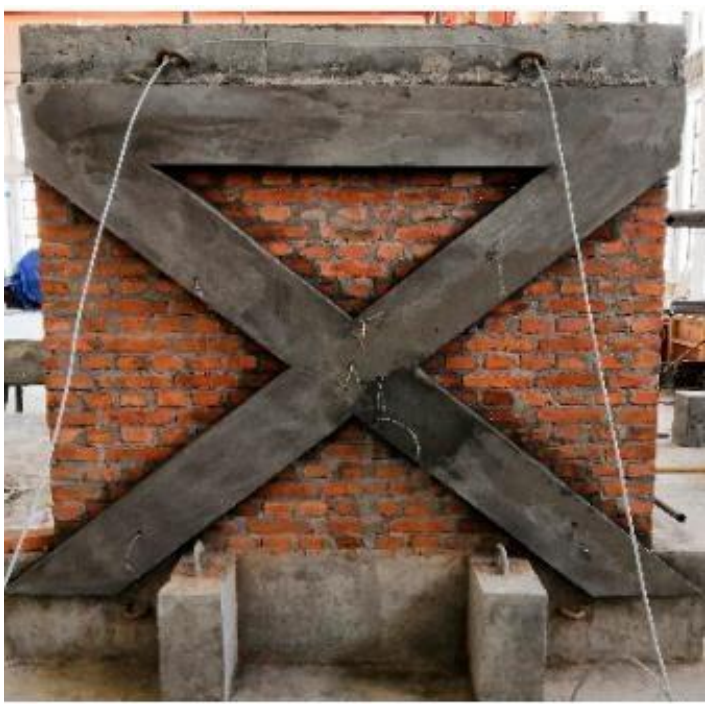

(c)

Fig. 13: RC reinforcement scheme, taken from (Dong et al., 2019) 


\section{Textile Reinforced Mortar (TRM)}

The Textile Reinforced Mortar (TRM) is obtained embedding fiber textile (Fig. 14) in an inorganic matrix.

TRM is also known as Fabric-Reinforced Cementitious Matrix (FRCM) and Textile-Reinforced Concrete (TRC) as stated by (Kouris and Triantafillou, 2018). It is usually applied on existing masonry structures to improve their mechanical characteristics. Many examples of this technique can be found in the literature.

A typical use of Basalt fiber mesh in retrofitting masonry wall is presented in Fig. 15.

Fossetti and Minafò (2016) have strengthened brick masonry column with Basalt Fiber-Reinforced Cementitious Matrix (BFRCM) Fig. 16 and steel wire collaring with two different types of mortar. The first type of mortar was prepared with hydraulic lime and sand, whereas the other one was composed with Portland cement, hydraulic lime and sand.

Papanicolaou et al. (2011) have retrofitted various masonry walls (brick shear walls, beam-column type walls and beam type walls) using five different types of textiles (Carbon, Basalt, E-glass, Polyester fiber and Polypropylene net). C-FRCM was also tested by (Faella et al., 2010).
Tuff masonry walls were retrofitted with a Cement-based Matrix-coated alkali resistant Glass grid system (CMG + TMR) as reported by (Prota et al., 2006). During the experiment different combination of innovative Cementitious Matrix-Grid CMG are created and applied on one or both sides of the tuff masonry wall.

Babaeidarabad et al. (2014) have used layers of Fiber Reinforced Cementitious Matrix FRCM with carbon and mortar cementitious element to retrofit six unreinforced masonry clay brick walls.

Akhoundi et al. (2018a-b) have also used textile glass fiber meshes embedded in mortar to retrofit the brick masonry infilled frames.

TRM strengthened brickwork walls have been tested by (Bernat et al., 2013). The walls were retrofitted with various combinations of TRM. They use various combinations of single layer of glass fiber grid and Portland-based mortar, glass fiber grid and lime-based mortar and carbon fiber grid and pozzolan-based mortar. They also tested two wall samples, with double layered fiber grids embedded into lime-based and Portland-based mortars. Other two sample walls are additionally retrofitted with six and nine fiber grid connectors.

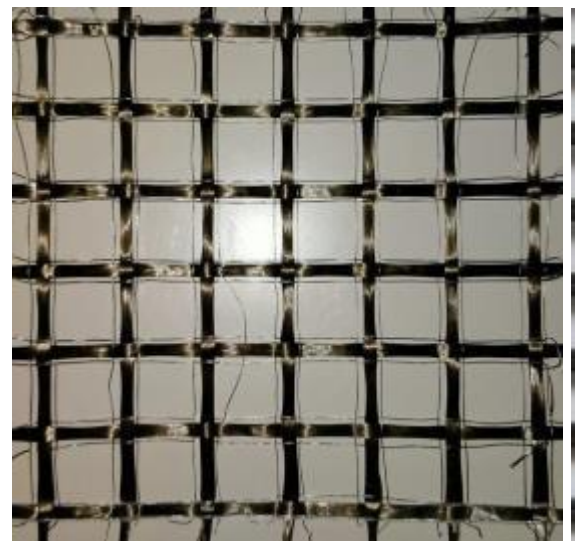

Basalt fabric

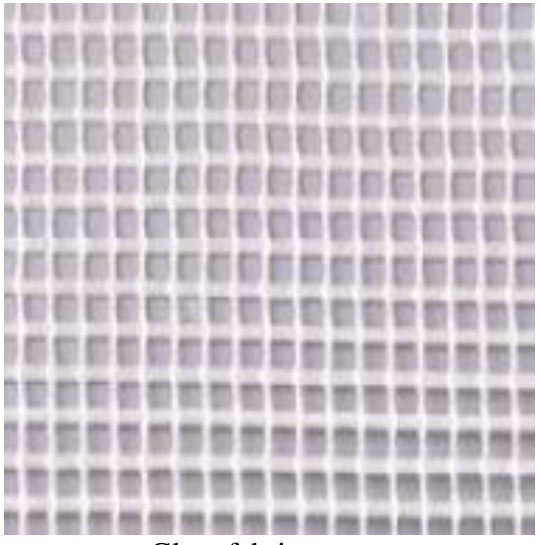

Glass fabric

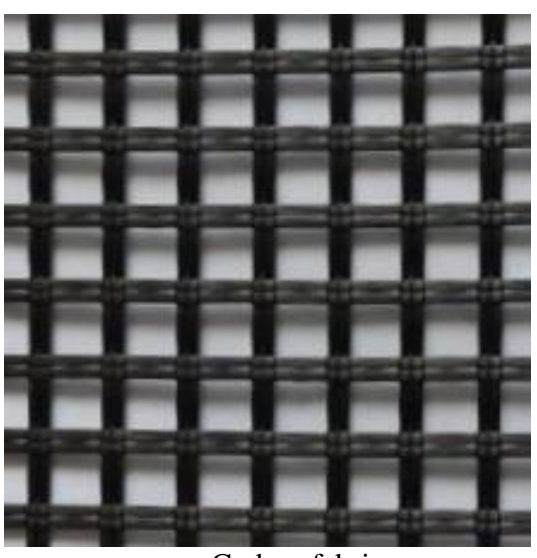

Carbon fabric

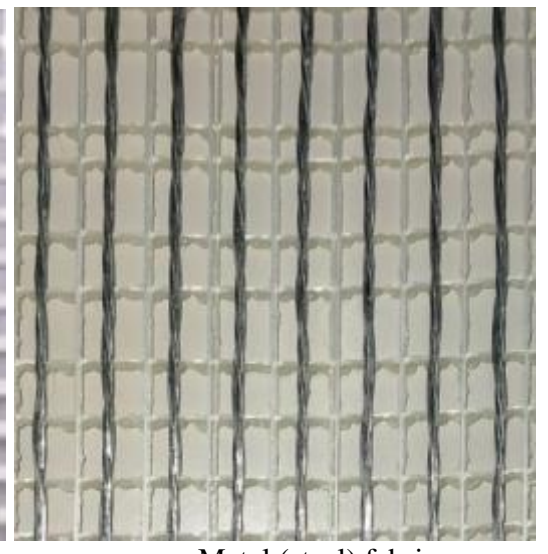

Metal (steel) fabric

Fig. 14: Fibers in textile form 


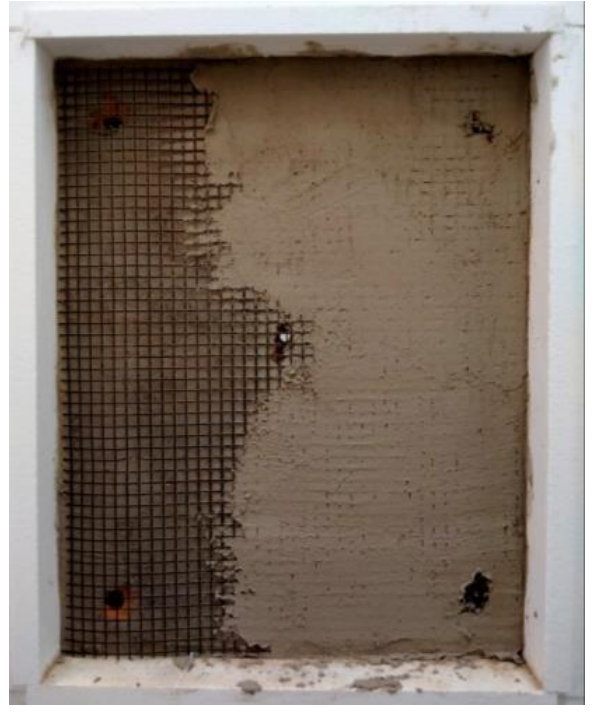

Fig. 15: TRM retrofitting

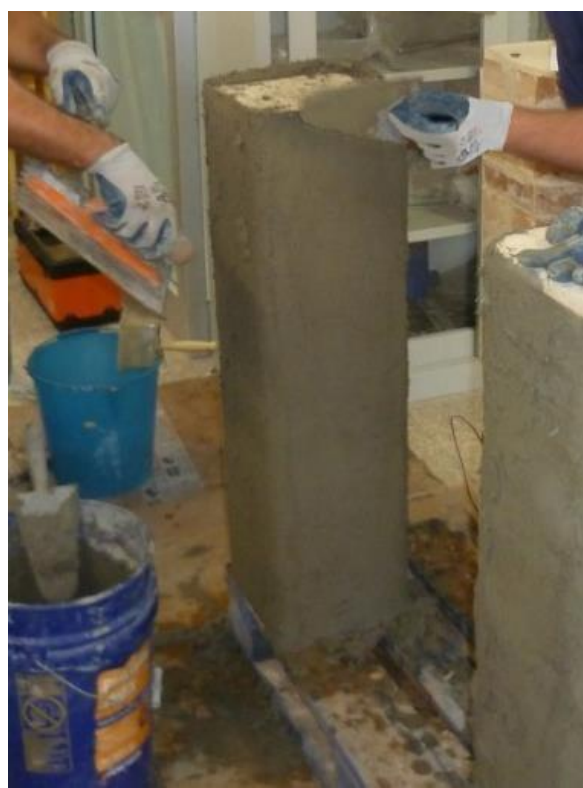

Fig. 16: BFRCM reinforcement (Fossetti and Minafò, 2016)

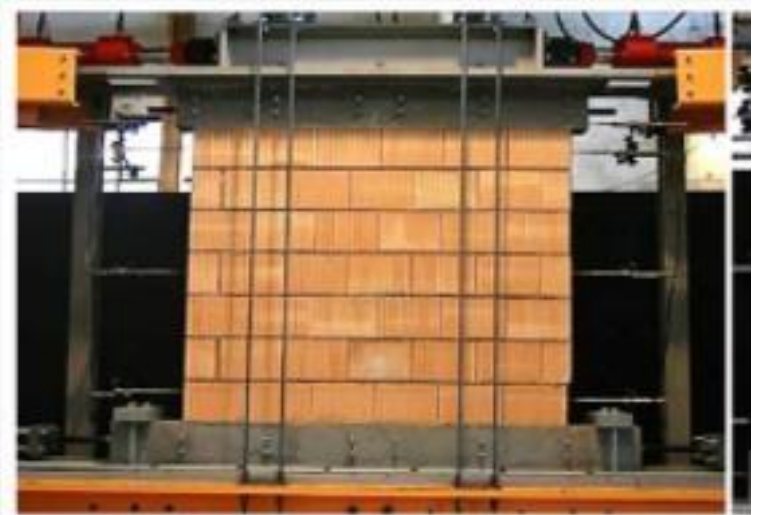

(a)

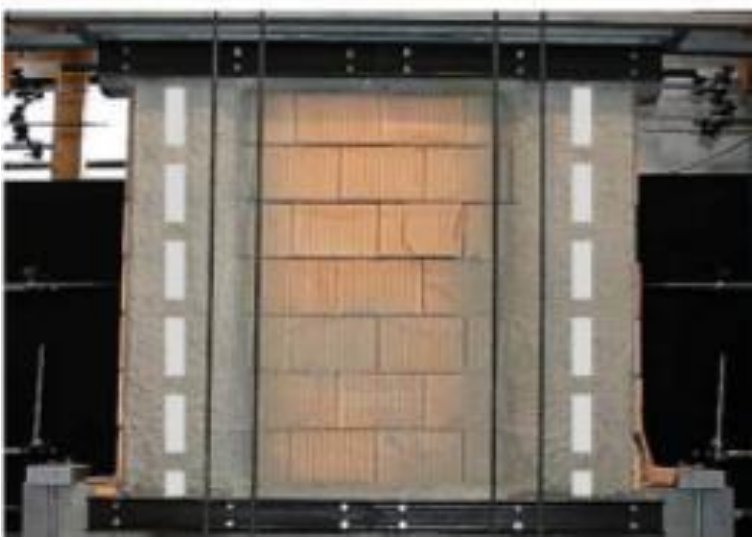

(b)

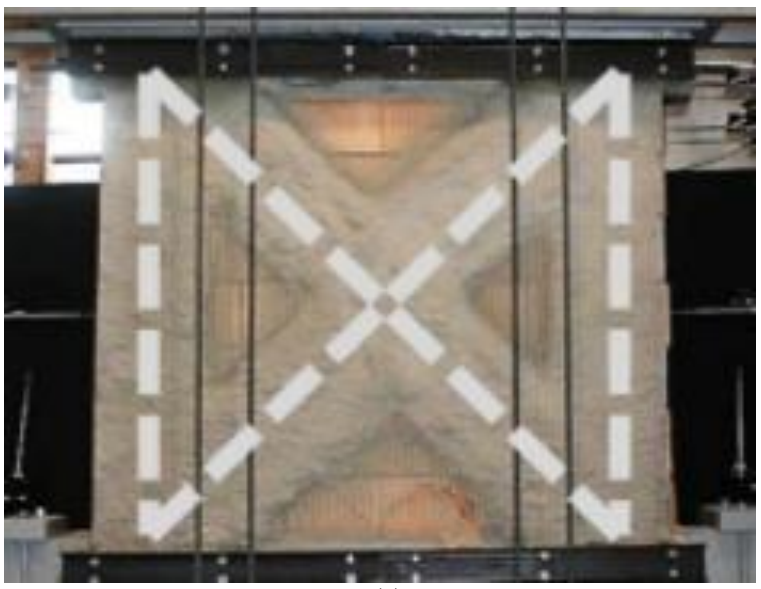

(c)

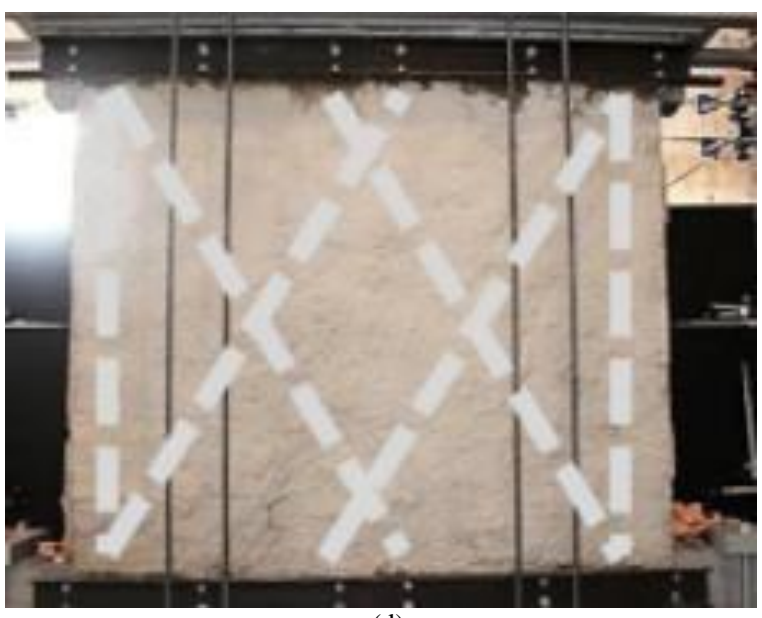

(d)

Fig. 17: Carbon mesh for retrofitting masonry walls (Bischof and Suter, 2014)

De Santis et al. (2019) the walls were tested unreinforced and then the tuff and stone walls are repaired and retrofitted on both sides with Steel Reinforced Grout (SRG) strips and Basalt Textile Reinforced Mortar (BTRM), respectively and thereafter these walls were tested again. 
For the first one, a unidirectional Ultra High Tensile Strength Steel (UHTSS) textile was put on the masonry wall, whereas for, BTRM retrofitting, the bidirectional basalt mesh was applied all over the stone wall with transversal connectors. For both cases lime-based mortar was used.

To achieve the static and seismic retrofitting of masonry wall (Fig. 17) (Bischof and Suter, 2014) have sprayed a mortar mixture on single and applied bidirectional coated carbon mesh strips.

Gattesco et al. (2015) used five types of GFRP mesh along with three different types of mortars in various combinations to retrofit four different types of masonry walls. The transversal and longitudinal fibers impregnated in resin have been crisscrossed to form the GFRP mesh.

Furtado et al. (2020) have retrofitted masonry walls made of hollow clay horizontal bricks, by using polypropylene mesh and strong Glass Fiber mesh (GFRP) along with M5 class mortar for plastering and steel connectors to anchor the textile mesh, as in Fig 18c.

Righetti et al. (2016) have used GFRP grids with two different dimensions along with lime based or cement baaed mortar, to reinforce the historic Masonry, Fig. 19.

In (Barducci et al., 2020), Fiber-Reinforcement Cementitious Matrix (FRCM) is applied on a brick substrate. The composites were prepared using basalt textile fiber coupled with four different mortar matrices.

\section{Fibers used for Masonry Retrofitting}

\section{Fiber Reinforced Polymer (FRP)}

All man-made or natural fiber reinforced with plastic or polymer matrix material can be defined as Fiber Reinforced Polymer or FRP, the nomenclature commonly known among the professionals.

Considering its lightweight and strength, the FRP composites are widely used in civil engineering applications, like new construction or retrofitting. See (Smits, 2016) for bridges, (Shamsuddoha et al., 2013) for underwater steel pipeline, (Buchan and Chen, 2007) for concrete and masonry structures.

In addition, FRP are rust proof and have high strength-to-weight and stiffness-to-weight ratios, as highlighted by (Masuelli, 2013).

The Glass Fiber Reinforced Polymer (GFRP), Basalt Fiber Reinforced Polymer (BFRP) and Carbon Fiber Reinforced Polymer (CFRP), represent the main FRP groups (Fig. 20) and mostly used for masonry retrofitting.

Figure 21 presents the constitutive laws of different fibers in comparison with common steel used for rebars.

While automotive is still the main application field of FRP, they are acquiring more and more importance also in the construction sector, Fig. 22 and all the values are approximated.

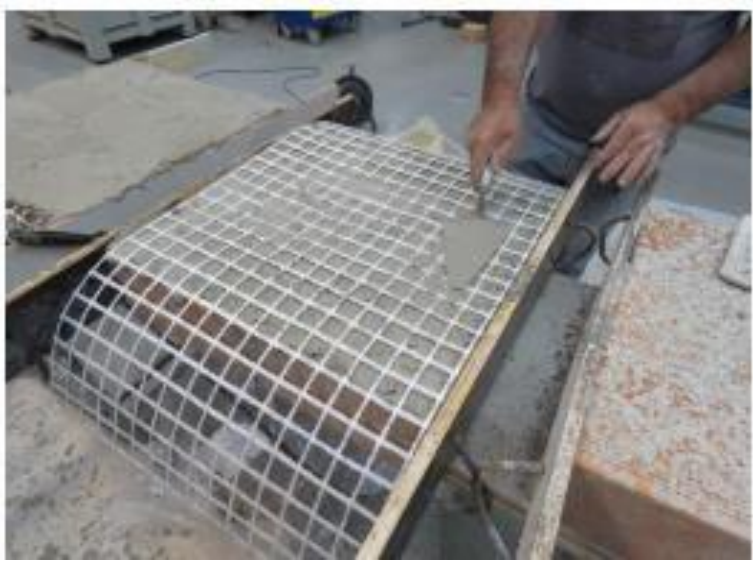

(a)

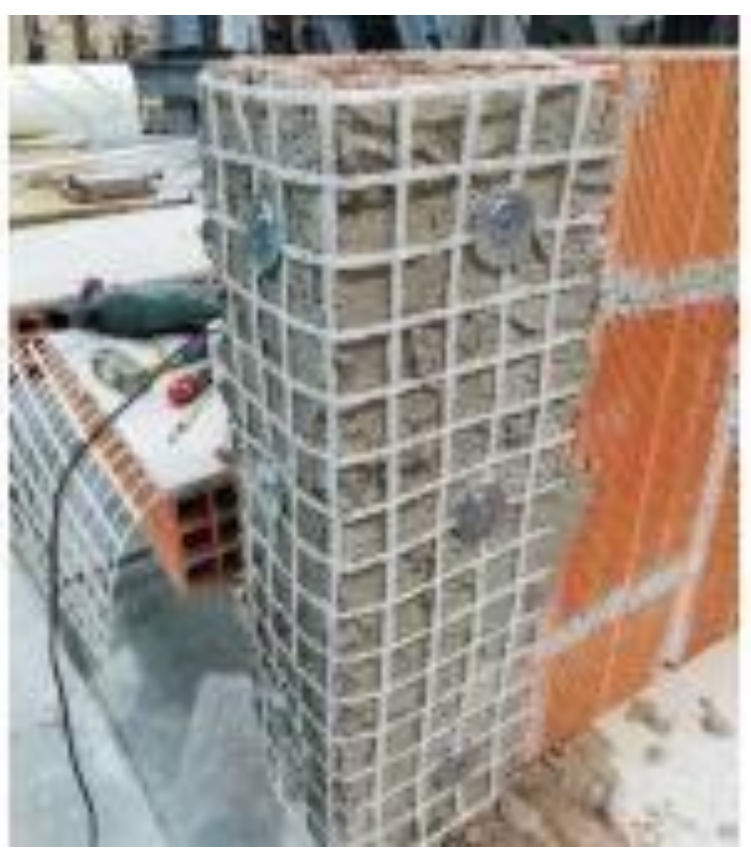

(b)
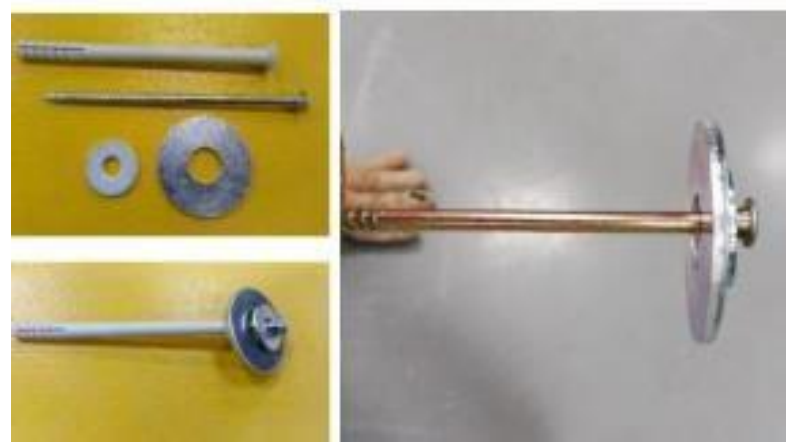

(c)

Fig. 18: (a) and (b) GFRP retrofitting, (c) steel connectors (Furtado et al., 2020) 
Arnas Majumder et al. / International Journal of Structural Glass and Advanced Materials Research 2021, Volume 5: 41.67 DOI: 10.3844/sgamrsp.2021.41.67

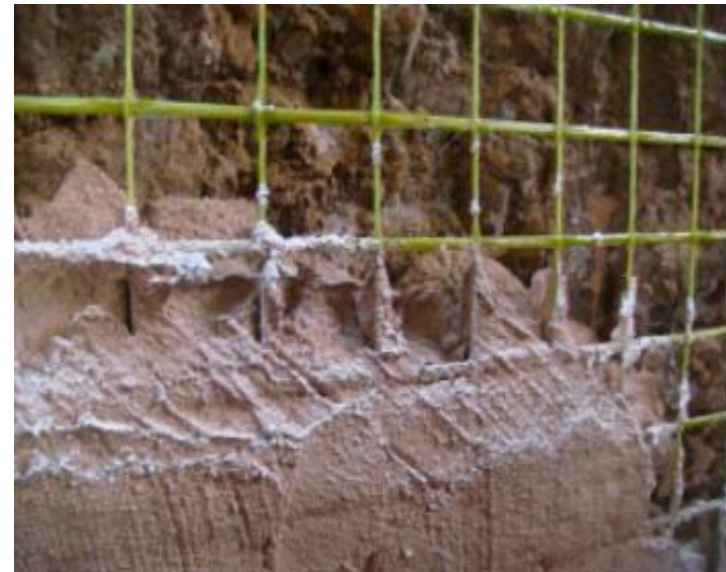

(a)

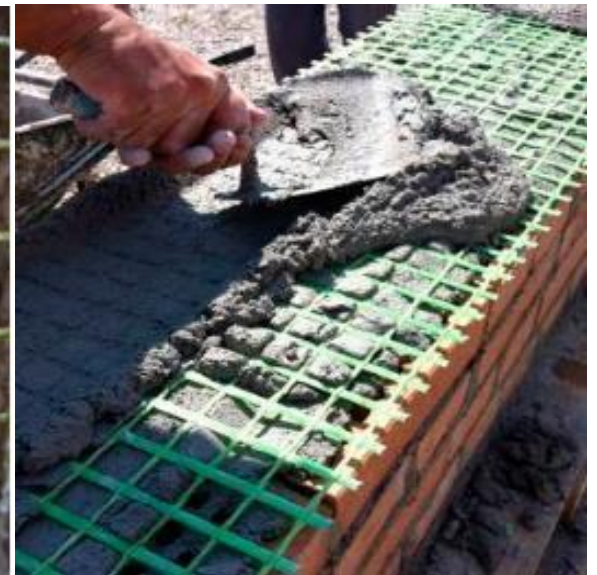

(b)

Fig. 19: (a) $66 \times 66 \mathrm{~mm}^{2}$ and (b) $33 \times 33 \mathrm{~mm}^{2}$ GFRP grids, (Righetti et al., 2016)

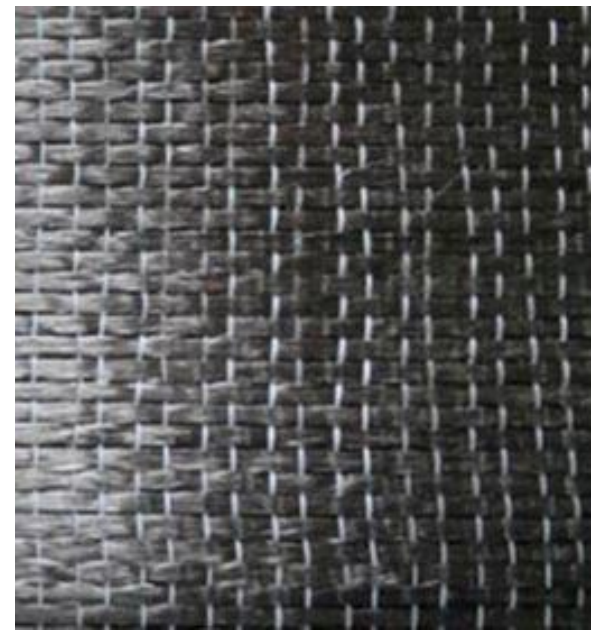

Basalt fiber sheet

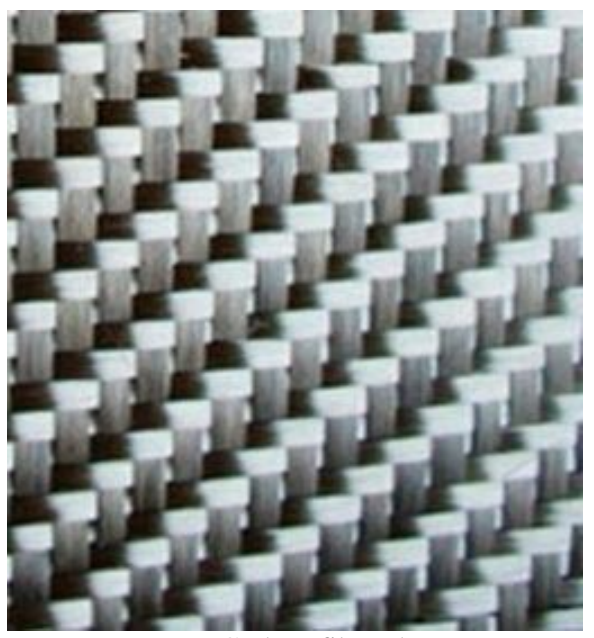

Carbon fiber sheet

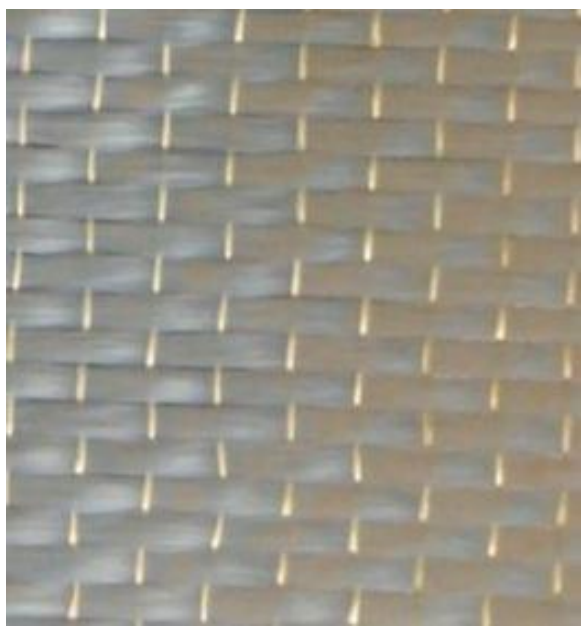

Glass fiber sheet

Fig. 20: Fiber Sheets (Zhao et al., 2017) 


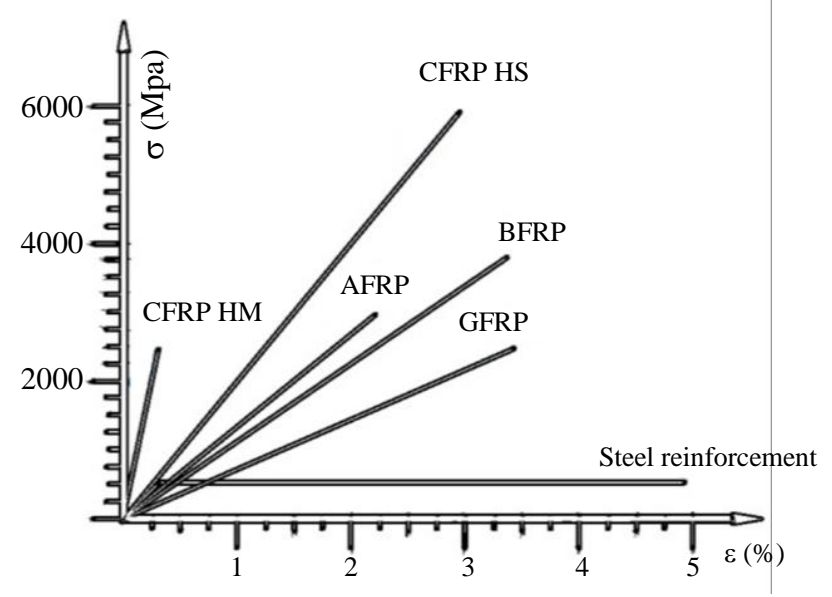

Fig. 21: constitutive laws for different fibers (Sonnenschein et al., 2016)

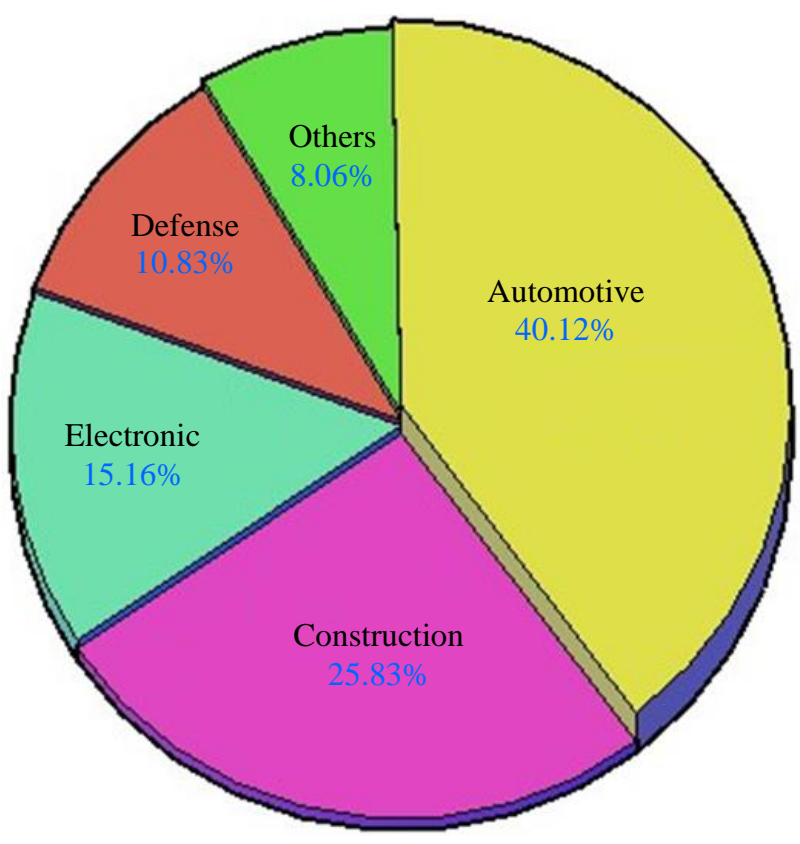

Fig. 22: Fiber Reinforced Polymer (FRP) composites global market, elaborated from: GVR (2017)

Actually, in recent years the use of natural fibers for masonry retrofitting has become a new trend to improve the constructions sustainability. Codispoti et al. (2015) have studied mechanical properties of Natural FRPs made from natural fibers like Jute, Hemp, Flex and Sisal, whereas, (Srinivasababu et al., 2009) have studied the okra, sisal and banana fiber reinforced polyester.

\section{Glass Fiber Reinforced Polymer (GFRP) Masonry Retrofitting}

Glass fiber, also known as fiberglass, is made of microfibers of glass combined with a plastic matrix (Masuelli, 2013). The glass fibers can be categorized into short fiber particles, yarns and textiles. As stated in (Bakis et al., 2002) the Glass fibers are predominantly used to prepare the early FRP's and the application of GFRP to masonry retrofitting is becoming quite common.

In (Marcari et al., 2007), tuff masonry walls were prepared with historically mortar and retrofitted with GFRP fixed on the walls with epoxy glue. Sivaraja et al. (2013) have strengthened burnt clay brick masonry walls with GFRP externally, glued with epoxy resin.

Solid clay brick masonry sample walls were retrofitted with externally bonded uniaxial and biaxial GFRP fabrics in (Mahmood and Ingham, 2011). GFPR application requires first the surfaces smoothing, then the application of a primer epoxy coat. After this it is possible to apply the epoxy-saturated glass fabric. Then 
the glass fiber anchors are placed inside the predrilled holes in order to apply others Glass fabric layer.

Kuzik et al. (2003) have retrofitted eight concrete brick samples with different dimensions but same type and characteristics of GFPR sheet.

Silva et al. (2008) reported the use of polyurea and GFRP to retrofit the walls. The concrete and clay masonry walls were prepared with the application of Portland cement-sand mortar. Different GFRP grid reinforced polyurea layouts, in either vertical or horizontal direction and single-and double-sided layouts were used.

Stratford et al. (2004) used the GFRP sheets to retrofit two different type of masonry walls, made of clay and concrete bricks. GFRP sheets are fixed on the surfaces with epoxy adhesive.

Kalali and Kabir (2012) have used GFRP and epoxy to retrofit a simulated Iranian style traditional wall constructed with solid clay bricks and cement mortar and both sides have been reinforced, Fig. 23.

\section{Basalt Fiber Reinforced Polymer (BFRP) Masonry Retrofitting}

Basalt fibers are obtained from the volcanic stone (Mahltig and Kyosev, 2018). The physical and mechanical performances of the basalt fiber is superior to the ones of glass fibers according to (Rajak et al., 2019).

Zhou et al. (2013) tested and retrofitted solid clay bricks walls with Basalt Fiber Reinforced Polymer (BFRP) analyzing the mechanical performances pre and post the damage tests. In (Lei et al., 2014), BFRP was used to retrofit the wall specimen with opening using mixed configurations. BFRP was attached to the wall using TGJ FRP-special adhesive.

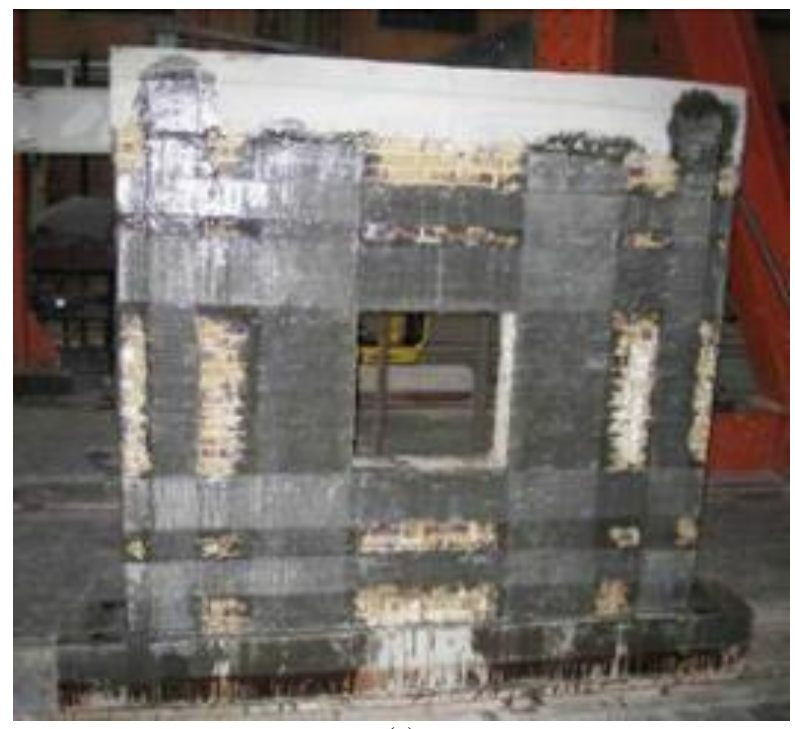

(a)

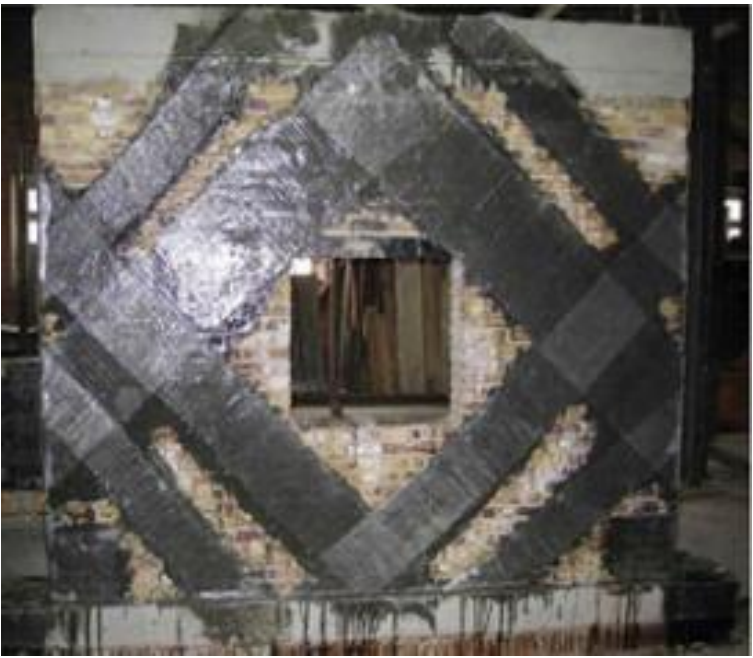

(b)

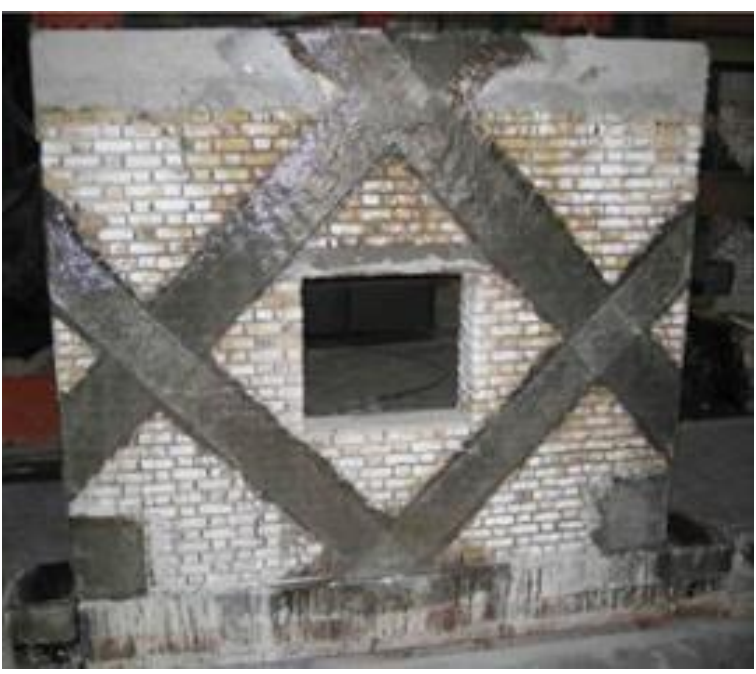

(c)

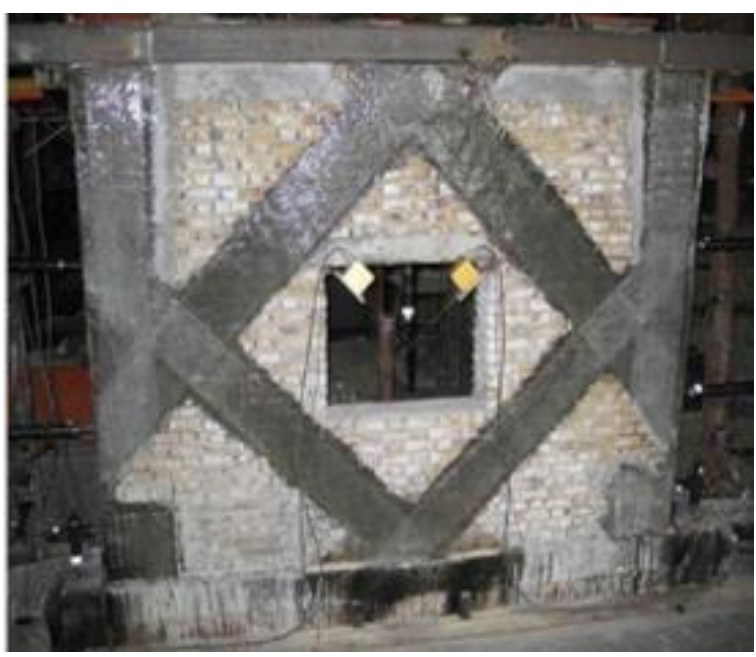

(d)

Fig. 23: Various schemes of the GFRP strengthened test specimens (Kalali and Kabir, 2012) 
After some on-site tests on wall samples inside a historical masonry building, (Tempesta, 2018) suggested to retrofit the building using BFRP and transversal element system, that provides grip to the basalt fiber strip and stability to the structure.

Padalu et al. (2019) have applied BFRP composite wrap in various configurations along with epoxy to retrofit unreinforced masonry. A Bi-directional basalt fabric has been used for this purpose. Padalu et al. (2020) have used epoxy resin to fix the BFRP to reinforce masonry wall. In this case also, the authors have used bi-directional weaved fiber.

\section{Carbon Fiber Reinforced Polymer Masonry Retrofitting}

$(C F R P)$

Carbon fiber is an organic fiber with a 5-10 micrometers diameter. It is also known as graphite fiber (when there is more than $99 \%$ of carbon Masuelli, 2013). It is a long chain of molecules tie together by carbon atoms, as stated in (Bhatt and Goe, 2017) and according to (Wu et al., 2020) it can be fabricated by fibrillation of acrylic resin.

CFRP is light and strong as stated in (Masuelli, (2013) and due its mechanical properties (high strength, excellent creep level, resistance to chemical effects, low conductivity, low density and high elastic modulus), it is suitable for new and historical masonry buildings retrofitting (Günaslan et al., 2014).

Carbon fiber was commercialized in 70's and due to higher cost, the CFRP was mainly used in the aviation industry until 1980, but currently given its lower cost and its excellent mechanical performance, it is widely used also in the building construction sector (Mouritz, 2012).

In the literature there are many civil structural applications of CFPR. Rahman and Ueda (2016) have used unidirectional CFRP fibers to retrofit masonry. They adopted a wet layup procedure where twocomponent epoxy resin is mixed and a primer layer is first applied where the composite is to be bonded, defined by (Lee, 2011). Epoxy putty (filler) have been used to fill the cavities on the wall to have smoother surface for fiber application. Fiber strip was fully saturated using resin and thereafter applied on the wall.

Arifuzzaman and Saatcioglu (2012) have conducted experiments on a masonry wall retrofitted with double layered epoxy bonded CFRP sheets. The sheets were placed parallel and perpendicular to the bed joint.

Marcari et al. (2007) also have used the grid and cross GFRP strips and epoxy, to retrofit tuff masonry walls.

As mentioned by (Hemeda, 2018), the circular masonry stone columns can be structurally retrofitted against the seismic load using the CRPF laminates. He reports on the cases of a historical church and other monuments reinforced in this way. Mahmood and Ingham (2011) have used pultruded CFRP plates and near-surface mounted rectangular bars to retrofit solid clay brick masonry walls.

Papanicolaou et al. (2011) have used one and two layered carbon FRPs bonded with epoxy resin to retrofit clay brick and stone block walls.

Recently, (Alecci et al., 2019) have used carbon FRP and two-component epoxy-based matrix, to repair previously tested and consequently damaged masonry walls.

\section{Natural Fiber Retrofitting (Plant and Animal Sources)}

The natural fibers are extracted from both plants and animal sources. In the literature it is possible to find several applications of natural fibers retrofitting that improve the structural and thermal insulation performance of masonry.

Codispoti et al. (2015) have developed a very extensive study to understand the mechanical performances of Natural Fiber Reinforced Polymers (NFRP), with the aim to strengthen masonry. The authors have chosen natural fibers like Jute, Sisal, Hemp and Flax. Epoxy resin, polyester resin (organic nature), cement-free mortar made with pozzolana lime and natural siliceous aggregate (inorganic nature) that are typically used for the matrix composites. The $\mathrm{NFRP}_{\text {epoxy }}, \mathrm{NFPR}_{\text {polyester }}$ and NFRCM were manufactured for mechanical tests. The tensile strength and Young's modulus of the tested fibers. Codispoti et al. (2015) also have stated that Flax fiber is the most suitable for manufacturing (composite martials) and useful for structural strengthening (in terms of strength and stiffness).

Raut and Gomez (2016) have shown the way to reuse the fibrous wastes derived from the oil palm production process, as building materials. Main recycled ingredients which have been added to with mortar element to create the mixture, are the residue of oil palm dry biomass and the fruit bunches of the palm oil plant, which are treated and transformed into usable products like Palm Oil Fly Ash (POFA). The Oil Palm Fibers (OPF) also derive from the same source of POFA and were mixed with the mortar to fabricate the experimental samples.

Furthermore, (Benmansour et al., 2014) have mixed palm fibers with cement and sand with the aim to produce and test new building insulating material.

Interestingly, (Valenza et al., 2015) have developed the mortars or plasters by using the sheep wool fiber mixed with cement matrix. These authors have pointed out that the waste wools might be used for this purpose. Till date the hemp as natural fiber reinforcement material has been used both in raw (cut in pieces) as well as in mesh form. Formisano et al. (2017) have prepared mortars and bricks reinforced with hemp fibers and hemp shives respectively.

Menna et al. (2015) have focused their work to retrofit both tuff and clay masonry walls with the application of hemp fiber composite grid along with 
Pozzolanic and lime-based mortar. The twisted hemp yarns were impregnated in a flexible epoxy resin. In this case the connecting $\mathrm{L}$ and $\mathrm{T}$ shape ties are also made of several longitudinal hemp fiber cords to strengthen and hold the fiber mesh applied on the wall.

There are a lot of examples of jute fiber used for concrete and mortar retrofitting in the literature. Recently, the usability of jute fibers along with lime mortar have studied by (Formisano et al., 2019) and recently (Ferrandez-García et al., 2020) have fabricated the cement panels using recycle jute fibers from jute bags, potato starch and Portland cement.

The plaster or mortar materials and fibers mixture consistency and therefore their usability is usually verified by the standard shaking table tests as reported in (Raut and Gomez, 2016; Formisano et al., 2017; 2019). In addition, other physical properties are studied like Bulk density in (Raut and Gomez, 2016); the water absorption in (Benmansour et al., 2014; Raut and Gomez, 2016; Formisano et al., 2019) and the apparent porosity in (Raut and Gomez, 2016).

The characteristics of building materials reinforced with natural fibers directly depend on the size and the amount of the fiber used in the mixture, as discussed in the Section Masonry Retrofitting: Structural and Thermal performance improvement

\section{Various Fiber Mesh Layouts}

In order to complete the fiber retrofitting description, it is important to present a synthetic review of the possible layouts.

In the literature it has been found that the application of the fiber mesh or net and its size, usable numbers and the layout combinations for masonry retrofitting can vary depending on the mechanical performance that to be achieved from the reinforcement. Figure 24 presents a synthetic review of the possible configurations.

The presence of empty spaces (like window, doors etc.) in the masonry walls makes the structure vulnerable towards the seismic events and the damage due to these activities could be minimized by retrofitting the walls with FRPs (Fig. 25).

The horizontal connectors are used in both FRP and TRM retrofitting, some schemes are shown in Fig. 26. The number of horizontal connectors (diatons) may vary depending on the type and size of the used fiber mesh and also on the personal choice and as studied and tested in (Giresini et al., 2020a) to ensure an optimum grip of the composite to the masonry.

\section{Masonry Retrofitting: Structural and Thermal Performance Improvement}

Another way to describe the various applications of masonry retrofitting with fiber-reinforced composite systems is to distinguish the purpose of the retrofitting. Indeed, the various fibers have been tested and used for structural, thermal and integrated retrofitting. Actually, the thermal insulation improvement due to the retrofitting yields to the reduction of energy consumptions used for the building climate control.

The integrated retrofitting represents the cases in which both structural and thermal performances of the wall are enhanced by the fibers. A classification of fibers based on their different retrofitting use has been proposed in Table 1.

If natural fibers are used to improve the mortar performances, fiber size and mixing percentage influence the results. In particular both structural and thermal performances results are inversely proportional to each other and this phenomenon has been observed in (Raut and Gomez, 2016), for palm oil fiber, in (Benmansour et al., 2014) date palm fiber and in (Valenza et al., 2015) for sheep wool fiber. The correct use of fiber in masonry retrofitting not only can improve the structural performance of the masonry structures but it can also improve its thermal insulation and boost the thermal performance of the building as whole.

The plant and animal based natural fibers ability, to work as insulating materials depend on the capability to trap the air in the fiber cavity, inside it or in the fibers matrix, notably in the case of fiber insulation panels, for example the sheep wool fiber insulation panel (Ahmed et al., 2019) and formation of compact insulating layers in cases where fibers are mixed with binders (Valenza et al., 2015).

When natural mineral fiber like basalt or man-made inorganic fibers like glass and carbon are used as FRP or in textile form as TRM, these fibers can also influence the overall heat transfer due to their presence in the structure, whereas to have a dedicated improvement in the thermal performance, these fibers must be used along with other heat insulating materials to achieve the thermal retrofitting, as notable in (Borri et al., 2016).

A synthetic scheme of the possible masonry retrofitting purposes of fibers is presented in Fig. 27.

\section{Structural Retrofitting}

The man-made fibers have been predominantly used for many years for structural retrofitting. Some of the examples are highlighted below.

GFRP retrofitted masonry walls as reported in (Sivaraja et al., 2013), were subjected to shock table tests, exposed to a simulated earthquake event. It has been observed that the total seismic energy withstanding capacity of the GFRP retrofitted sample is almost 20 times greater than the one of similar non-retrofitted sample.

Stratford et al. (2004) tested all the masonry walls subjected to a combination of vertical and in-plane shear load. The performance improvements are patent also in this case: $65 \%$ Increase in load-capacity for the GFRP strengthened clay walls, 38 and $63 \%$ for the concrete walls (lower value due to faulty production process). As reported by the authors, no change in the stiffness and deformationcapacity of the specimens have been observed. 
Arnas Majumder et al. / International Journal of Structural Glass and Advanced Materials Research 2021, Volume 5: 41.67 DOI: 10.3844/sgamrsp.2021.41.67

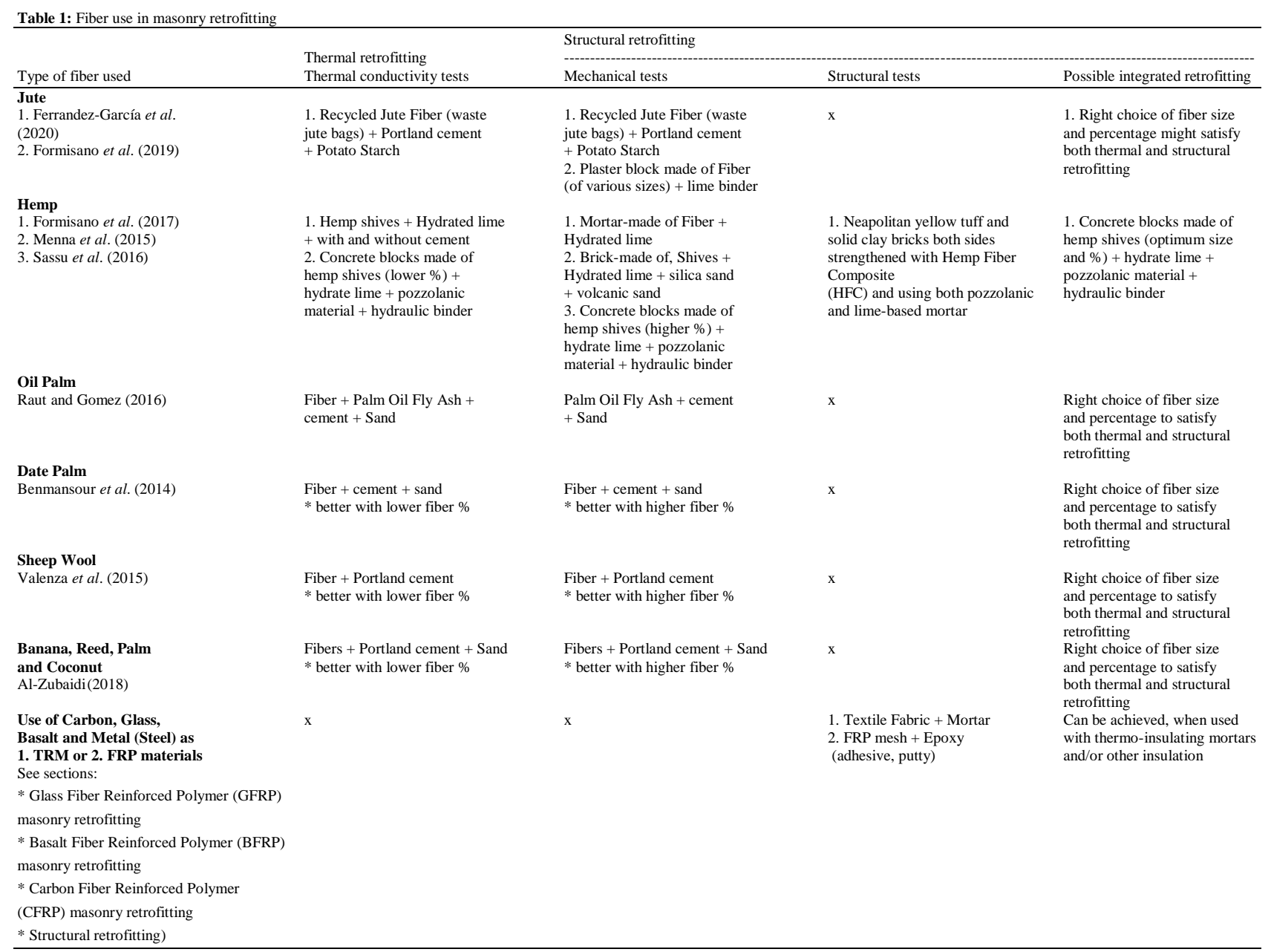
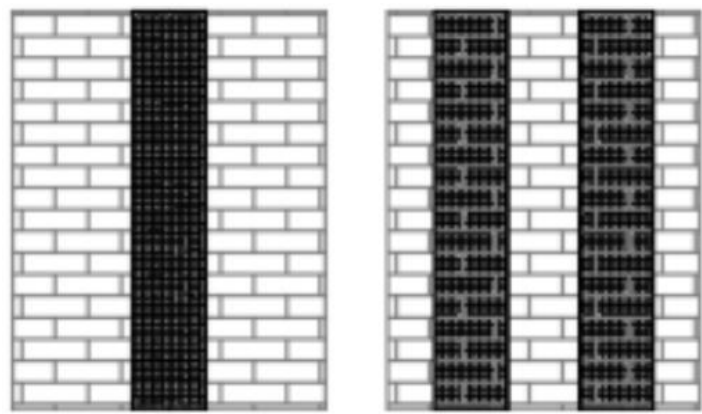

(a)

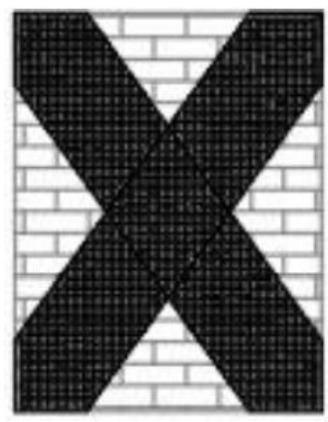

(c)

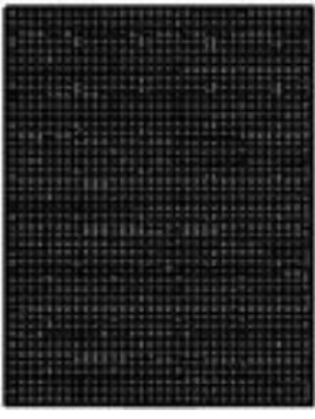

(d)
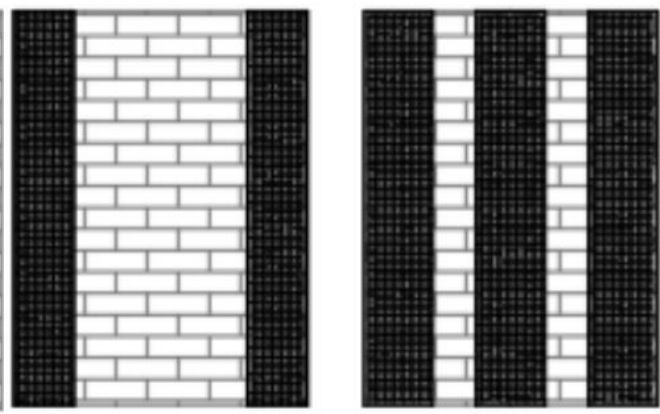

(b)
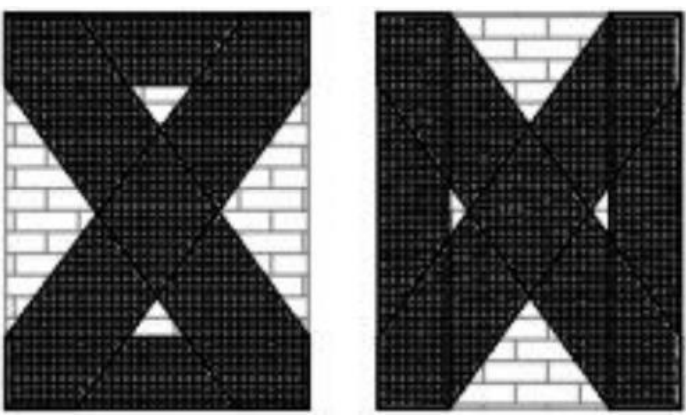

(e) 
Arnas Majumder et al. / International Journal of Structural Glass and Advanced Materials Research 2021, Volume 5: 41.67 DOI: 10.3844/sgamrsp.2021.41.67

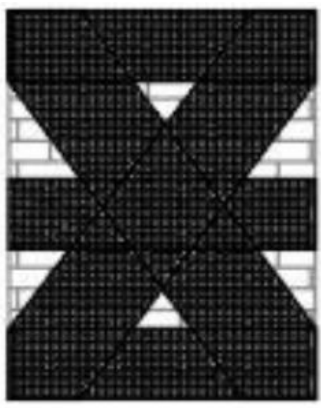

(f)



$(\mathrm{g})$

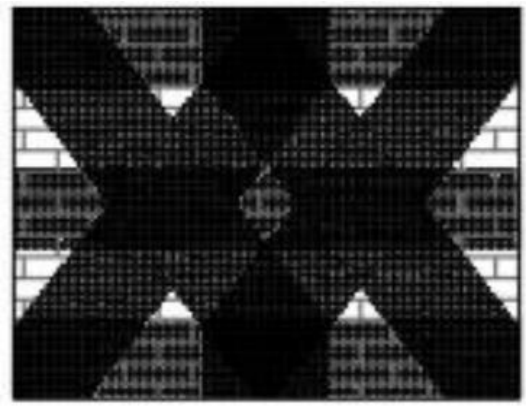

(h)

Fig. 24: Different FRP layouts (a) and (b) Vertical bending configuration; (c) Shear configuration; (d) Complete configuration; (e) and (f) Simple hybrid configurations; (g) and (h) Complex hybrid configurations

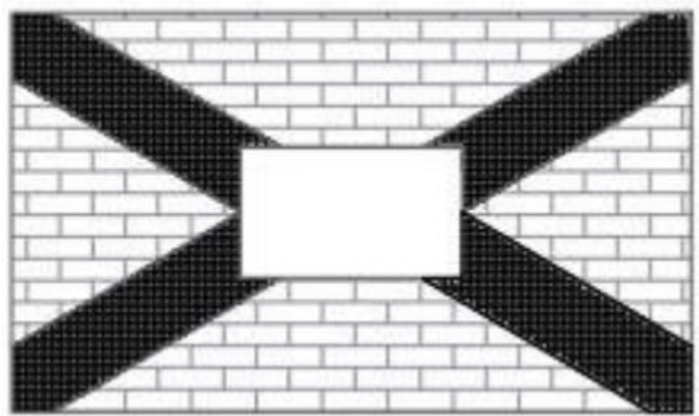

(a)

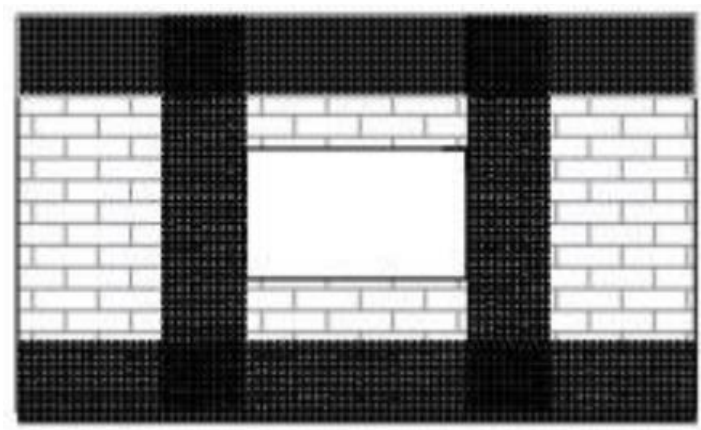

(c)

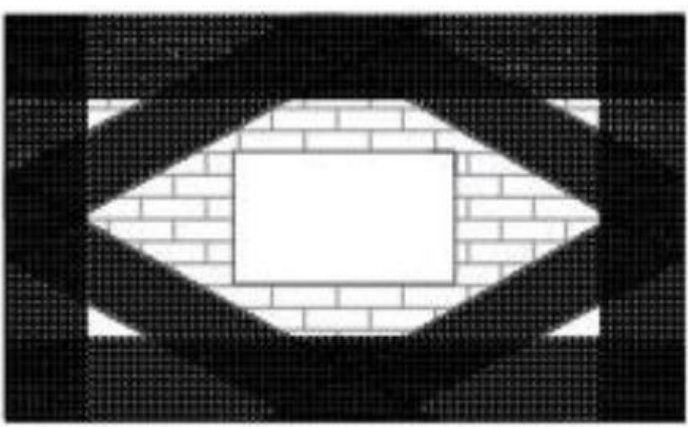

(e)

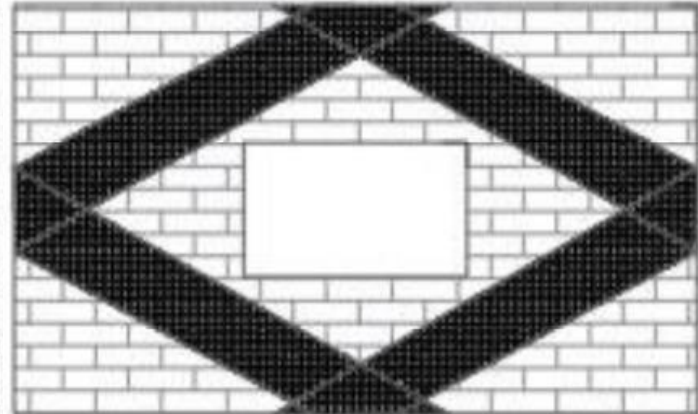

(b)

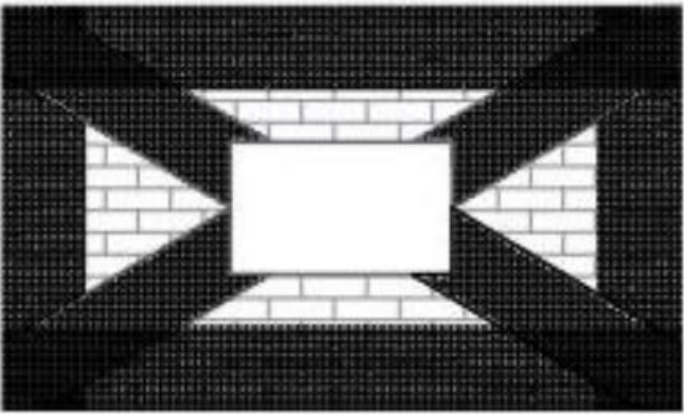

(d)

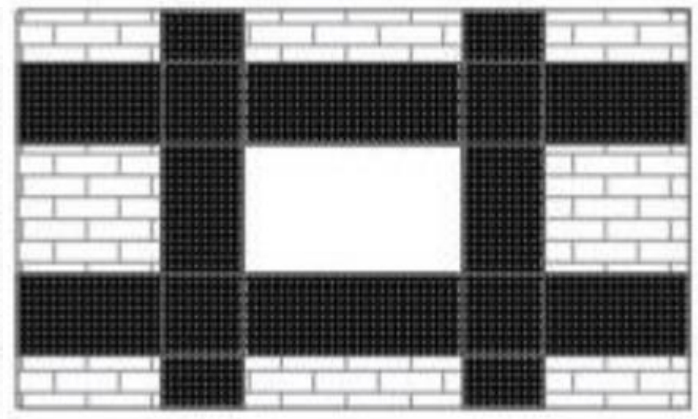

(f)

Fig. 25: Masonry wall structure with hollow space in the middle and FRP retrofitting schemes 
Arnas Majumder et al. / International Journal of Structural Glass and Advanced Materials Research 2021, Volume 5: 41.67 DOI: $10.3844 /$ sgamrsp.2021.41.67

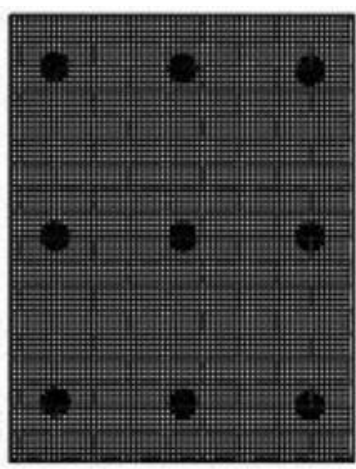

(a)

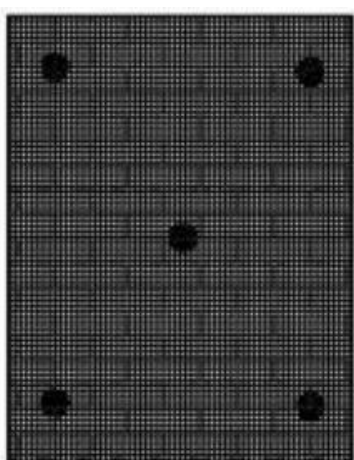



(b)

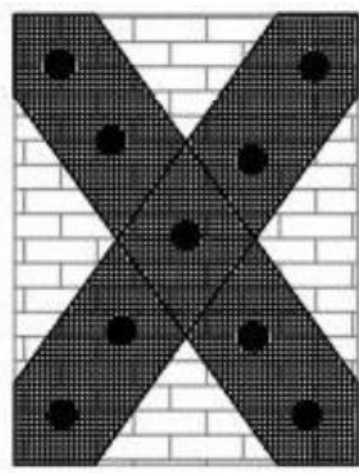

Fig. 26: TRM and FRP with horizontal connectors

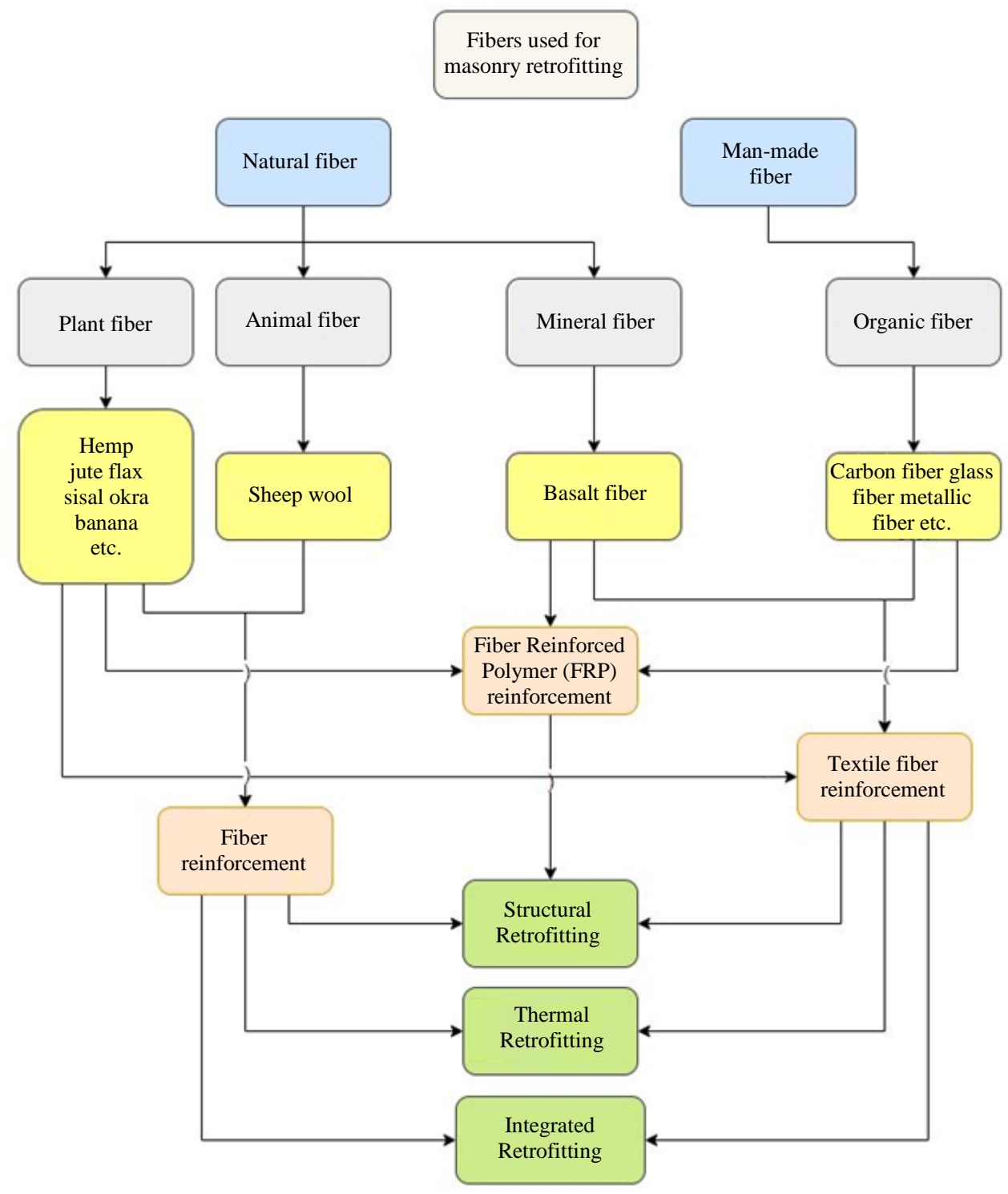

Fig. 27: Fiber use in Masonry retrofitting 
The in-plane share capacity of GFRP retrofitted masonry and concrete walls have been studied by (Silva et al., 2008). Improvements in shear capacity of the strengthened walls were significant and horizonal strips have demonstrated more effectiveness over vertical strips and at the same time when GFRPs are put on both wall sides their efficacy increased twice.

Cyclic loading was applied to study the out-of-plane flexural behavior of the GFRP retrofitted masonry walls by (Kuzik et al., 2003). They report excellent overall flexural performance and highlight that the linear response of the bending moment versus centerline deflection hysteresis and the variation in the wall stiffness and the ultimate strength depend on amount of bonded GFRP sheet reinforcement.

Kalali and Kabir (2012) have tested GFRP retrofitted masonry wall subjected to constant gravity load and under increasing in-plane loading cycle, obtaining improvement are the strength, deformation capacity and energy absorption.

Mahmood and Ingham (2011), have developed diagonal compression tests and report to achieve improvement in shear strength (up to $325 \%$ ), in ductility and toughness of the pultruded CFRP and GFPR retrofitted masonry.

Also, (Marcari et al., 2007) have used CFRP and GFRP strips applied on the walls using epoxy, for retrofitting tuff masonry walls and have studied the in-plane shear performance when these were subjected to monotonic shear-compression loading in a quasi-static test. Improvements in shear strength, lateral strength and nonsignificant variation of elastic stiffness have been reported.

Zhou et al. (2013) have studied the in-plane behavior of unreinforced and retrofitted with BFRP masonry subjected to static cyclic loading. Enhancement in shear capacity (44-61\%), whereas no difference from the initial stiffness was observed.

BFRP reinforced and the un-reinforced RC-brick masonry walls were tested to investigate in-plane behavior by (Lei et al., 2014). All the samples were subjected to low frequency cyclic loading. The application of BFPR enhances the lateral strength (16\%) both also the ultimate drift, the energy dissipation capacity and the bearing stability.

Padalu et al. (2019) have tested the wall samples (including BFRP retrofitted ones) in one-way bending condition under two point out-of-plane loading by putting wallettes horizontally. Comparing BFRP retrofitted samples with unreinforced masonry samples it is possible to assess improvement of flexural strength (up to 6.4 times), the maximum midspan displacement (up to 30 times), effective stiffness (up to 5.3 times).

Padalu et al. (2020) have studied the out-of-plane behavior of the reinforced masonry walls. The unreinforced masonry walls were structurally retrofitted with BFRP + Epoxy resin, Basalt Fiber Mesh (BFM)
$+1: 4$ cement-sand mortar and welded wire mesh $+1: 3$ cement-sand mortar. A notable improvement approx. $73 \%$ in flexural capacity, $482 \%$ in stiffness and $72 \%$ in the energy absorbing have been observed.

Tempesta (2018) has stated that a structure retrofitted using BFRP with transversal element system presents an excellent resistance to shear as well as to the combined compressive and bending actions.

Rahman and Ueda (2016) have reported on the use of CFPR to reinforce the masonry walls and found an improvement of in-plane shear strength but a reduction in the ductility. Also, CFRP application can modify the elastic stiffness.

Arifuzzaman and Saatcioglu (2012) have demonstrated that with CFRP a masonry wall can withstand to an improvement of $150 \%$ in the applied lateral force. Also, the wall shear capacity, the flexural capacity and the overall behavior under applied seismic loading are enhanced.

Righetti et al. (2016) have conducted the on-site shear compression, Fig. 28a and diagonal compression tests Fig. 28b on the masonry walls retrofitted with GFRP and inorganic mortar and as stated enhancement of the mechanical behavior was achieved.

Alecci et al. (2019) have done diagonal compression tests on masonry walls before damaging these walls and after repairing using CFRP strips placed at various patterns and the shear strength found to be similar for damaged and undamaged walls.

Furtado et al. (2020) have studied the out-of-plane behavior of the masonry infill walls, strengthened with Glass fiber textile and mortar. The GFRP-TRM increase the flexural strength and deformation capacity by $54 \%$ and 4.18 times respectively. Also the plaster enhances the approx. $57 \%$ the flexural capacity.

Papanicolaou et al. (2011) have tested both CFRP and TRM retrofitting by applying out-of-plane or in-plane loading on masonry walls. TRM produce better performances in terms of maximum load and displacements at failure in the case of out-of-plane loading but for in-plane loading the effectiveness of TRM is lower than the one of FRP. It has been observed that the TRM retrofitted samples present a higher deformation capacity $(15-30 \%$ more). The authors have concluded that TRM retrofitting is more promising for out-of-plane than in-plane seismic loading.

Prota et al. (2006) have experimented the in-plane behavior of the TRM + CMG retrofitted tuff masonry walls. With the CMG grid application, it has been found that the average shear strength increases by factor equal to 2 .

Fossetti and Minafò (2016) have developed uniaxial compressive tests until failure, on the BFRCM and steel retrofitted masonry columns. Strength improvement has been observed for the column with BFRCM jacketing while an increase in ultimate strain and energy absorption when reinforcing steel wires has been observed. 
Barducci et al. (2020), have compared the bond behavior of the FRCM systems, composed of basalt fiber and four different types of mortar matrices.

Actually, when compared to natural fibers and Natural FRPs, the man-made fibers and their FRPs are less sustainable due to the constraints associated with their production processes like fossil fuel depletion, air pollution, smog and acidification as mentioned in (Masuelli, 2013; Osugi et al., 2009). Therefore, to contribute to the global sustainability reducing the $\mathrm{CO}_{2}$ production it is important to look for natural materials for retrofitting existing buildings or for the construction of new ones.

An interesting example of the quest towards developing sustainable building materials is reported in (Sassu et al., 2016), Fig. 29. In this case new kinds of block are obtained by mixing hemp shives and cork granules with natural hydraulic lime, used as binder. They achieved mixed results in terms of mechanical performances with the hemp and cork samples. The hemp samples have low mechanical performances but are effective as insulating panels, basement layers or separating walls. The cork samples have demonstrated optimum structural properties achieving quite high maximum stain, compressive strength and tensile strength.

Formisano et al. (2020) developed a jute fiber reinforced mortar by mixing jute fiber and lime (NTC, 2018). The value of the average failure compression stress has remained above the class M10-NTC 18 standard for almost all fiber-reinforced mortars, Fig. 30. Therefore, these products can be used as building product, also in seismic zones.

Hemp fibers and shives have been used to prepare mortar and bricks by (Formisano et al., 2017) in order to evaluate their mechanical behaviors. It has been found that the performance increment was of about $29 \%$ in reinforced mortar specimens under bending tests. The ultimate displacement of reinforced specimen is $0.63 \mathrm{~mm}$, whereas for the unreinforced specimen is about $0.49 \mathrm{~mm}$.

Menna et al. (2015) have developed diagonal compression tests on retrofitted tuff and clay masonry wall panels with hemp fiber mesh, pozzolanic and lime-based mortar.

The authors have studied the in-plane behaviors strengthened Neapolitan Yellow Tuff (NYT) and clay masonry panels. The tests have proved a betterment in the mechanical properties for the reinforced materials. Maximum shear strength increased by a factor about 2-3 and 5 in the case of NYT panels and clay panels respectively.

The hempcrete (hemp shives + lime based linder) blocks with various density have been prepared in (Elfordy et al., 2008). The authors reported that blocks need to be denser and stronger to have a structural use. A comparison of advantages and disadvantages of natural and men made fibers is presented in Table 2.

\section{Thermal-Retrofitting Building Materials}

Mineral wool and plastics are the mostly used as thermal insulation materials occupying approx. 52 and $41 \%$ of the market shares, respectively (Asdrubali et al., 2015). These products have detrimental effect towards the environment considering that: These are produced by using non-renewable and non-organic materials that are difficult to be recycled or re-used. Also, the above-mentioned thermal insulation materials are known to be hazardous towards human health, as expressed in (De Vuyst et al., 1995).

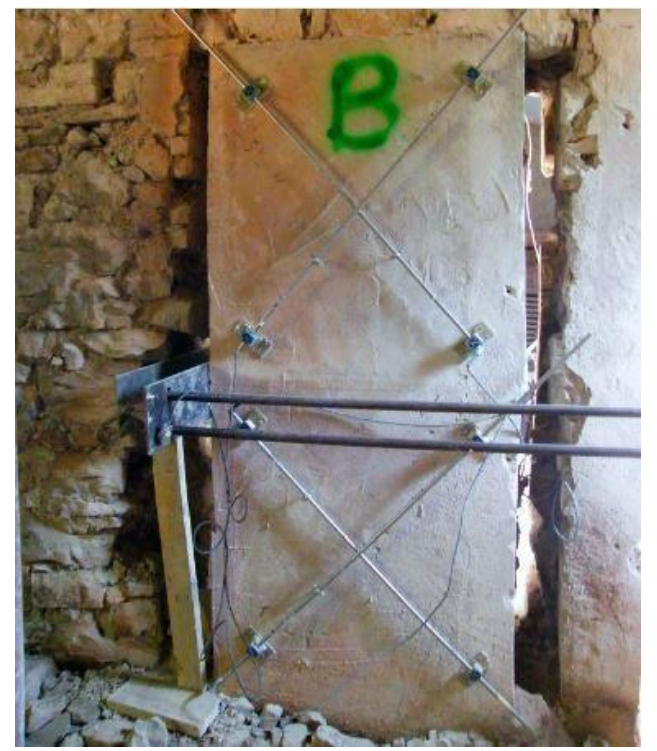

(a)

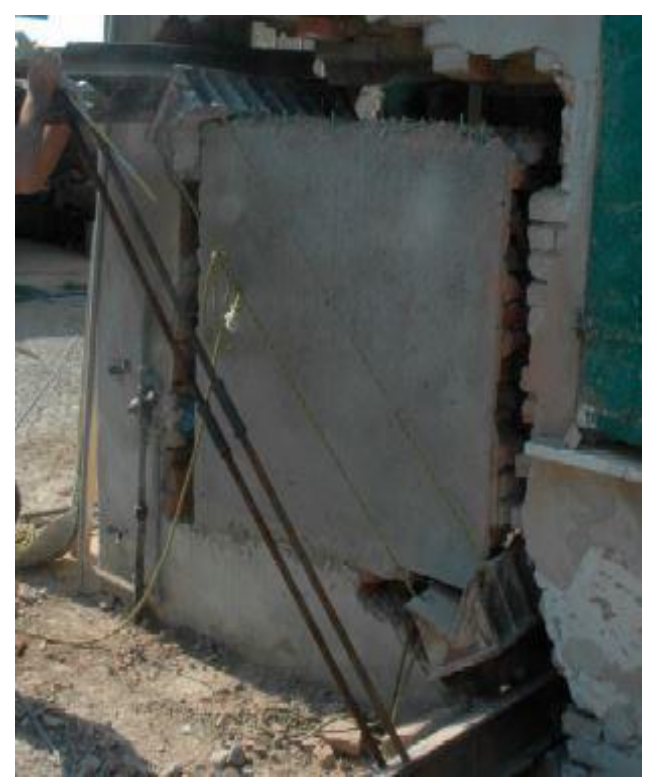

(b)

Fig. 28: (a) Shear compression test, (b) Diagonal compression test (Righetti et al., 2016) 


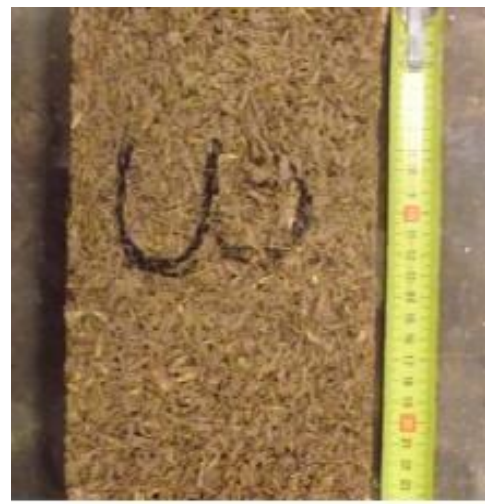

(a)

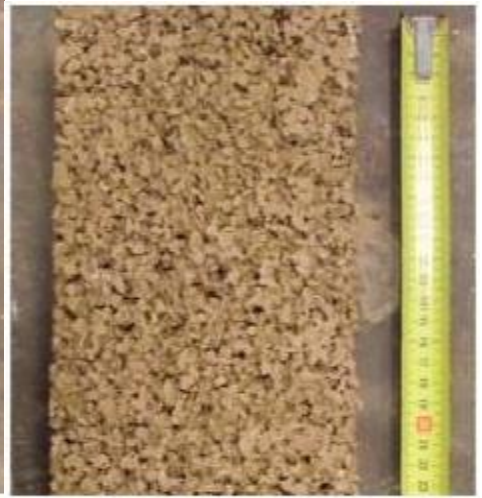

(b)

Fig. 29: Blocks of (a) hemp and (b) cork granules (Sassu et al., 2016)

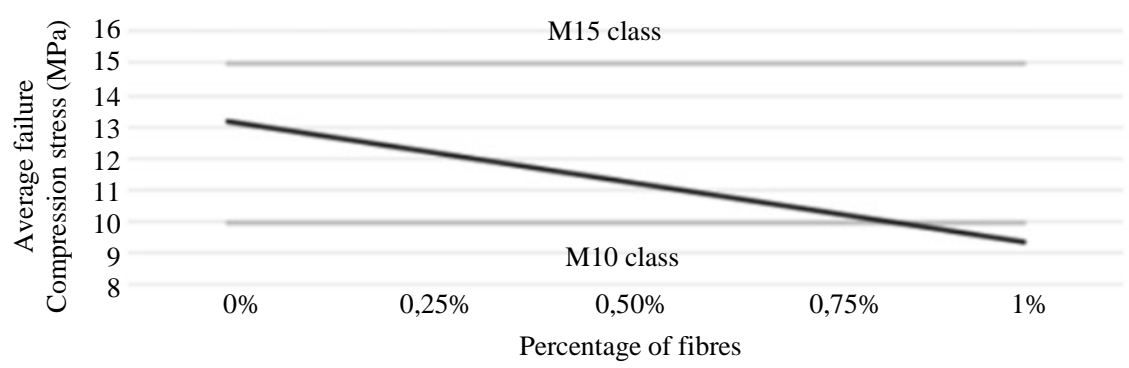

Fig. 30: Influence of the fiber percentage in Average failure compression stress (Formisano et al., 2020)

Table 2: Comparison of advantages and disadvantages of man-made and natural fiber retrofitting

\begin{tabular}{|c|c|c|c|}
\hline \multicolumn{2}{|l|}{ Man-made FRP } & \multicolumn{2}{|c|}{ Natural fiber retrofitting/natural FRP } \\
\hline Advantages & Disadvantages & Advantages & Disadvantages \\
\hline 1. Higher mechanical & 1. High production cost & 1. Low production cost & 1. Lower mechanical performance \\
\hline performance & 2. Less sustainable-more & 2. Lower environmental Impact & 2. Sustainable but new to the users \\
\hline 2. Well known & energy consumption & 3. Mostly recyclable when used & 3 Perfect candidates for Integrated \\
\hline characterizati on data & 3. Limitation to recyclability & with other natural/biom aterials & retrofitting \\
\hline $\begin{array}{l}3 \text { Majorly used for } \\
\text { structural retrofitting } \\
\text { 4. Durability }\end{array}$ & 4. Glass fiber is Hazardous & 4. Non-Hazardous & $\begin{array}{l}\text { 4. Degradable, sometime need } \\
\text { treatment }\end{array}$ \\
\hline
\end{tabular}

Valenza et al. (2015) have used Sicilian sheep wool (washed and unwashed) at various proportion along with cement to prepare samples and have studied their thermo-structural properties. Among all other conclusions, they have expressed that the specimen with fiber size and proportion respectively equal to 1 (mm) and $46 \%$ has the best and lowest thermal conductivity value equal to $0.096(\mathrm{~W} / \mathrm{mK})$.

Elfordy et al. (2008) have reported that the hempcrete block with lower density $417\left(\mathrm{~kg} / \mathrm{m}^{3}\right)$ has better thermal conductivity $0.179(\mathrm{~W} / \mathrm{mK})$ in comparison to 0.485 $(\mathrm{W} / \mathrm{mK})$ when density is $551\left(\mathrm{~kg} / \mathrm{m}^{3}\right)$. Therefore, the blocks with lower conductivity value can be used as thermal insulating material.

As reported also in (Sassu et al., 2016) the hemp shives might be used to create insulating panels. Raut and Gomez (2016; Benmansour et al., 2014), it has been observed that higher percent of fiber in the composite mixture directly influence the thermal conductivity values providing lower values. Therefore, the authors have stated that these products might be usable for the thermal insulation of buildings.

\section{Integrated Retrofitting Building Materials}

When the retrofitting strategy is aimed at enhancing both structural and thermal properties, the integrated retrofitting might be an approach. It is quite difficult to achieve the ultimate improvement of both these properties with the same materials. Indeed, structural strength and thermal resistance have opposite trend.

Being new concept, the optimization of both structural and thermal insulation properties simultaneously needs extensive research work therefore it is not always cost effective. Whereas, (Giresini et al., 2020b) have conducted an analytical study, to evaluate the cost-effectiveness of the integrated approaches for the masonry building façades.

Raut and Gomez (2016) prepared mortars using oil palm fibers, available as waste product to attain certain 
thermo-structural characteristics and to have a sustainable building material. The optimized values are obtained when fiber addition is equal to $1,5 \%$ of the weight of the binder and the compressive strength is compliant with (ASTM C270, 2007). Also, an increase in the thermal performance and in the flexural strength have been detected. Therefore, this product might be used as integrated building material.

Benmansour et al. (2014), reported on the thermal and mechanical properties of mortar reinforced with date palm fibers. Although the goal was to develop an insulating building material. Authors have claimed that these innovative mortars are suitable for thermal and structural, integrated retrofitting use when fiber concentration is low and the optimum ratio is found to be 5-15\%. Valenza et al. (2015), fabricated environmentally friendly mortar and plaster with good thermal performance by mixing sheep wool with cement. It has been found that shorter fibers improve the thermal conductivity value. An increase in fiber content deteriorate the compressive strength but improve the thermal conductivity and it is true up to certain combination of fiber size and percentage. Therefore, the optimum thermo-structural value found to be with when the fibers length is equal to $6 \mathrm{~mm}$ and weight content to $13 \%$.

Cement composite reinforced with natural fibers of banana, reed, palm and coconut have been investigated in (Al-Zubaidi, 2018). Size, morphology and fiber contents affects the reinforcement performance. Therefore, right combination might enhance integrated retrofitting. Ferrandez-García et al. (2020) have studied thermo-mechanical properties cement panels retrofitted with recycled jute fiber (from jute bags) and potato starch plasticizer. As claimed by the authors, the thermal and mechanical properties are in line with European building standards. GFRP grids were inserted into thermo-insulating mortars by (Borri et al., 2016) who reported to have achieved low value for conductivity $0.106(\mathrm{~W} / \mathrm{mK})$ for the sample fabricated using plaster board and mortar with clay, cork and natural lime with Glass Fiber Reinforced grid (GFRP grid). This technique improves also the lateral load capacity.

\section{Conclusion and Perspectives}

This study presented a review on the current state of knowledge of both structural and thermal masonry retrofitting with a particular attention to the use of fiberreinforced composed systems. This topic is quite relevant considering that the largest part of the European traditional buildings is composed of masonry buildings and most of these did not follow the ant-seismic and thermal standards. Thus, the needs of structural and thermal retrofitting is clear. On the other hand, the buildings impact on the environment represents one of the most important challenge for mankind.

For this reason, it is necessary to reduce the construction materials environmental impact finding new and more sustainable solutions. Natural fibers represent a promising approach to this target and jute, hemp, oil palm, flax, but also sheep wool are sustainable materials that can play a key role for building retrofitting.

An integrated approach aimed at improving both thermal and structural performances faces the problem that materials that have good structural performances usually present quite high conductivity values yielding to poor thermal insulation performance. For this reason, it is necessary to engineer materials in order obtain integrated solution. For example, it is possible to obtain retrofitting panels that are composed by different layers of different materials. In this context the use of fibers embedded in insulating mortars or other materials seems another interesting option.

Future developments in this field are expected both at materials level and at the structural level. The future of existing masonry constructions seems bonded to the future of fibers.

\section{Funding Information}

The financial support of the Autonomous Region of Sardinia under Grant PO-FSE 2014-2020, CCI: 2014IT05SFOP021, through the project "Retrofitting, Rehabilitation and Requalification of the Historical Cultural Architectural Heritage (R3-PAS)" is acknowledged by Flavio Stochino.

\section{Author's Contributions}

Arnas Majumder: Conceptualization, validation and formal analysis, methodology, investigation, data curation, writing-original draft preparation.

Flavio Stochino: Conceptualization, validation and formal analysis, writing-original draft preparation.

Fernando Fraternali and Enzo Martinelli: Conceptualization, validation and formal analysis, writing-review and editing.

\section{Ethics}

This article is original and contains unpublished and published material. All the already published figures are taken from OA publications and the original source is correctly cited. The corresponding author confirms that all of the other authors have rea read and approved the manuscript and no ethical issues involved with declaration of no conflict of interest

\section{References}

Ahmed, A., Qayoum, A., \& Mir, F. Q. (2019). Investigation of the thermal behavior of the natural insulation materials for low temperature regions. Journal of Building Engineering, 26, 100849. https://doi.org/10.1016/j.jobe.2019.100849 
Aizi, D. E., \& Kaid-Harche, M. (2020). Mechanical Behavior of Gypsum Composites Reinforced with Retama monosperma Fibers. In Multidisciplinary Digital Publishing Institute Proceedings (Vol. 63, No. 1 , p. 40). https://doi.org/10.3390/proceedings2020063040

Akhoundi, F., Vasconcelos, G., Lourenço, P., Silva, L. M., Cunha, F., \& Fangueiro, R. (2018a). In-plane behavior of cavity masonry infills and strengthening with textile reinforced mortar. Engineering Structures, 156, 145160. https://doi.org/10.1016/j.engstruct.2017.11.002

Akhoundi, F., Vasconcelos, G., \& Lourenço, P. (2018b). In-plane behavior of infills using glass fiber shear connectors in textile reinforced mortar (TRM) technique. International Journal of Structural Glass and Advanced Materials Research, 2(1), 1-14. https://doi.org/10.3844/sgamrsp.2018.1.14

Alecci, V., Barducci, S., D'Ambrisi, A., De Stefano, M., Focacci, F., Luciano, R., \& Penna, R. (2019). Shear capacity of masonry panels repaired with composite materials: Experimental and analytical investigations. Composites Part B: Engineering, 171, 61-69. https://doi.org/10.1016/j.compositesb.2019.04.013

Ali Shah, S. M., Shahzada, K., Gencturk, B., \& Memon, S. A. (2017). Retrofitting of full-scale confined masonry building using ferro-cement overlay. Journal of Performance of Constructed Facilities, 31(5), 04017079. https://doi.org/10.1061/(ASCE)CF.19435509.0001060

Almeida, C., Guedes, J. P., Arêde, A., Costa, C. Q., \& Costa, A. (2012). Physical characterization and compression tests of one leaf stone masonry walls. Construction and Building Materials, 30, 188-197. https://doi.org/10.1016/j.conbuildmat.2011.11.043

AL-Zubaidi, A. B. (2018, May). Effect of natural fibers on mechanical properties of green cement mortar. In AIP Conference Proceedings (Vol. 1968, No. 1, p. 020003). AIP Publishing LLC. https://doi.org/10.1063/1.5039162

Amaral, M. C. D., Zonatti, W. F., Silva, K. L. D., Karam Junior, D., Amato Neto, J., \& Baruque-Ramos, J. (2018). Industrial textile recycling and reuse in Brazil: case study and considerations concerning the circular economy. Gestão \& Produção, 25(3), 431-443. https://doi.org/10.1590/0104-530x3305

Arifuzzaman, S., \& Saatcioglu, M. (2012). Seismic Retrofit of Load Bearing Masonry Walls by FRP sheets and Anchors Sheets and Anchors. In Proceedings of the 15th World Conference on Earthquake Engineering.

Army, U. S. (1993). Standard Practice for Shotcrete. US Army corps of Engineers, Washington, USA. 20020626:123
Asdrubali, F., D'Alessandro, F., \& Schiavoni, S. (2015). A review of unconventional sustainable building insulation materials. Sustainable Materials and Technologies, 4, 1-17. https://doi.org/10.1016/j.susmat.2015.05.002

Ashraf, M., Khan, A. N., Naseer, A., Ali, Q., \& Alam, B. (2012). Seismic behavior of unreinforced and confined brick masonry walls before and after ferrocement overlay retrofitting. International Journal of Architectural Heritage, 6(6), 665-688. https://doi.org/10.1080/15583058.2011.599916

ASTM C270. (2007). Standard specification for mortar for unit masonry. West Conshohocken, PA, USA: ASTM

Babaeidarabad, S., Caso, F. D., \& Nanni, A. (2014). Out-ofplane behavior of URM walls strengthened with fabricreinforced cementitious matrix composite. Journal of Composites for Construction, 18(4), 04013057. https://doi.org/10.1061/(ASCE)CC.19435614.0000457

Bakis, C. E., Bank, L. C., Brown, V., Cosenza, E., Davalos, J. F., Lesko, J. J., ... \& Triantafillou, T. C. (2002). Fiber-reinforced polymer composites for construction-State-of-the-art review. Journal of composites for construction, 6(2), 73-87. https://doi.org/10.1061/(ASCE)10900268(2002)6:2(73)

Bambach, M. R. (2020). Direct Comparison of the Structural Compression Characteristics of Natural and Synthetic Fiber-Epoxy Composites: Flax, Jute, Hemp, Glass and Carbon Fibers. Fibers, 8(10), 62. https://doi.org/10.3390/fib8100062

Barbosa, M. C, Rosa, S. E. S. D, Correa, A. R, Dvorsak, P., \& Gomes, G. (2004). Synthetic fibers sector and supply of petrochemical intermediates.

Barducci, S., Alecci, V., De Stefano, M., Misseri, G., Rovero, L., \& Stipo, G. (2020). Experimental and analytical investigations on bond behavior of basaltFRCM systems. Journal of Composites for Construction, 24(1), 04019055. https://doi.org/10.1061/(ASCE)CC.19435614.0000985

Basaran, H., Demir, A., \& Bagci, M. (2013). The behavior of masonry walls with reinforced plaster mortar. Advances in Materials Science and Engineering, 2013. https://doi.org/10.1155/2013/436946

Basu, B., Bursi, O. S., Casciati, F., Casciati, S., Del Grosso, A. E., Domaneschi, M., ... \& Rodellar, J. (2014). A European Association for the Control of Structures joint perspective. Recent studies in civil structural control across Europe. Structural Control and Health Monitoring, 21(12), 1414-1436. https://doi.org/10.1002/stc.1652 
Benmansour, N., Agoudjil, B., Gherabli, A., Kareche, A., \& Boudenne, A. (2014). Thermal and mechanical performance of natural mortar reinforced with date palm fibers for use as insulating materials in building. Energy and Buildings, 81, 98-104. https://doi.org/10.1016/j.enbuild.2014.05.032

Benzar, B. E., Park, M., Lee, H. S., Yoon, I., \& Cho, J. (2020). Determining retrofit technologies for building energy performance. Journal of Asian Architecture and Building Engineering, 19(4), 367-383. https://doi.org/10.1080/13467581.2020.1748037

Bernat, E., Gil, L., Roca, P., \& Escrig, C. (2013). Experimental and analytical study of TRM strengthened brickwork walls under eccentric compressive loading. Construction and Building Materials, 44, 35-47. https://doi.org/10.1016/j.conbuildmat.2013.03.006

Bhatt, P., \& Goe, A. (2017). Carbon fibres: production, properties and potential use. Material Science Research India, 14(1), 52-57. https://doi.org/10.13005/msri/140109

Bischof, P., \& Suter, R. (2014). Retrofitting masonry walls with carbon mesh. Polymers, 6(2), 280-299. https://doi.org/10.3390/polym6020280

Borri, A., Corradi, M., Sisti, R., Buratti, C., Belloni, E., \& Moretti, E. (2016). Masonry wall panels retrofitted with thermal-insulating GFRP-reinforced jacketing. Materials and Structures, 49(10), 3957-3968. https://doi.org/10.1617/s11527-015-0766-4

Buchan, P. A., \& Chen, J. F. (2007). Blast resistance of FRP composites and polymer strengthened concrete and masonry structures-A state-of-the-art review. Composites Part B: Engineering, 38(5-6), 509-522. https://doi.org/10.1016/j.compositesb.2006.07.009

Christou, P., \& Elliotis, M. (2016). Construction and retrofit methods of stone masonry structures in cyprus. The Open Construction \& Building Technology Journal, 10(1). https://doi.org/10.2174/1874836801610010246

Codispoti, R., Oliveira, D. V., Olivito, R. S., Lourenço, P. B., \& Fangueiro, R. (2015). Mechanical performance of natural fiber-reinforced composites for the strengthening of masonry. Composites Part B: $\quad$ Engineering, 77, 74-83. https://doi.org/10.1016/j.compositesb.2015.03.021

De Santis, S., De Canio, G., de Felice, G., Meriggi, P., \& Roselli, I. (2019). Out-of-plane seismic retrofitting of masonry walls with Textile Reinforced Mortar composites. Bulletin of Earthquake Engineering, 17(11), 6265-6300. https://doi.org/10.1007/s10518019-00701-5

De Santoli, L., \& DÁmbrosio Alfano, F. R. (2014). Energy efficiency and HVAC systems in existing and historical buildings. The Rehva European HVAC Journal, 51(6), 44-48.
De Vuyst, P., Dumortier, P., Swaen, G. M., Pairon, J. C., \& Brochard, P. (1995). Respiratory health effects of man-made vitreous (mineral) fibres. European Respiratory Journal, 8(12), 2149-2173. https://doi.org/10.1183/09031936.95.08122149

Dell'Isola, M., Alfano, F. D. A., Giovinco, G., \& Ianniello, E. (2012). Experimental analysis of thermal conductivity for building materials depending on moisture content. International Journal of Thermophysics, 33(8-9), 1674-1685. https://doi.org/10.1007/s10765-012-1215-z

Deopura, B. L., \& Padaki, N. V. (2015). Synthetic textile fibres: polyamide, polyester and aramid fibres. In Textiles and Fashion (pp. 97-114). Woodhead Publishing. https://doi.org/10.1016/B978-1-84569-9314.00005-2

Dong, K., Sui, Z. A., Jiang, J., \& Zhou, X. (2019). Experimental study on seismic behavior of masonry walls strengthened by reinforced mortar cross strips. Sustainability, 11(18), 4866. https://doi.org/10.3390/su11184866

EC. (2019a). New rules for greener and smarter buildings will increase quality of life for all Europeans. Brussels. (European Commission).

EC. (2019b). Brussels. (European Commission), EPBD (Energy performance of buildings directive).

Elfordy, S., Lucas, F., Tancret, F., Scudeller, Y., \& Goudet, L. (2008). Mechanical and thermal properties of lime and hemp concrete ("hempcrete") manufactured by a projection process. Construction and Building Materials, 22(10), 2116-2123. https://doi.org/10.1016/j.conbuildmat.2007.07.016

ElGawady, M. A., Lestuzzi, P., \& Badoux, M. (2006, March). Retrofitting of masonry walls using shotcrete. In 2006 NZSEE Conference, Paper (Vol. 45).

ElGawady, M., Lestuzzi, P., \& Badoux, M. (2004, July). A review of conventional seismic retrofitting techniques for URM. In 13th international brick and block masonry conference (pp. 1-10).

EN ISO 52016-1: (2017). Thermal performance of buildings and building components http://store.uni.com/catalogo/norme/root-categoriecen/cen/cen-tc-89/en-iso-52016-1-2017

EN. (1998). Eurocode 8: Design of structures for earthquake resistance, 2004. https://eurocodes.jrc.ec.europa.eu/showpage.php? id $=138$

EP, C.E.U. (European Parliament, Council of the European Union), 2010. Energy performance of buildings directive (EPBD) 2010/31/EU.

EP, C.E.U. (European Parliament, Council of the European Union) 2012. Energy efficiency Directive (EED).

EP, C.E.U. (European Parliament, Council of the European Union). 2018. Energy Performance of Buildings. 
Faella, C., Martinelli, E., Nigro, E., \& Paciello, S. (2010). Shear capacity of masonry walls externally strengthened by a cement-based composite material: An experimental campaign. Construction and Building Materials, 24(1), 84-93. https://doi.org/10.1016/j.conbuildmat.2009.08.019

Ferrandez-García, M. T., Ferrandez-Garcia, C. E., GarciaOrtuño, T., Ferrandez-Garcia, A., \& Ferrandez-Villena, M. (2020). Study of Waste Jute Fibre Panels (Corchorus capsularis L.) Agglomerated with Portland Cement and Starch. Polymers, 12(3), 599. https://doi.org/10.3390/polym12030599

Ferrara, G., Caggegi, C., Martinelli, E., \& Gabor, A. (2020). Shear capacity of masonry walls externally strengthened using Flax-TRM composite systems: experimental tests and comparative assessment. Construction and Building Materials, 261, 120490. https://doi.org/10.1016/j.conbuildmat.2020.120490

Ferretti, E. (2019). Wire Ropes and CFRP Strips to Provide Masonry Walls with Out-Of-Plane Strengthening. Materials, 12(17), 2712. https://doi.org/10.3390/ma12172712

Formisano, A., Chiumiento, G., \& Dessì, E. J. (2020). Laboratory Tests on Hydraulic Lime Mortar Reinforced With Jute Fibres. The Open Civil Engineering Journal, 14(1). https://doi.org/10.2174/1874149502014010152

Formisano, A., Chiumiento, G., \& Fabbrocino, F. (2019, September). Experimentation on Lime Mortars Reinforced with Jute Fibres: Mixture Workability and Mechanical Strengths. In Conference of the Italian Association of Theoretical and Applied Mechanics (pp. 1869-1880). Springer, Cham. https://doi.org/10.1007/978-3-030-41057-5_150

Formisano, A., Dessì Jr, E., \& Landolfo, R. (2017, November). Mechanical-physical experimental tests on lime mortars and bricks reinforced with hemp. In AIP conference proceedings (Vol. 1906, No. 1, p. 090006). AIP Publishing LLC. https://doi.org/10.1063/1.5012363

Fossetti, M., \& Minafò, G. (2016). Strengthening of masonry columns with BFRCM or with steel wires: An experimental study. Fibers, 4(2), 15. https://doi.org/10.3390/fib4020015

Furtado, A., Rodrigues, H., Arêde, A., \& Varum, H. (2020). Impact of the Textile Mesh on the Efficiency of TRM Strengthening Solutions to Improve the Infill Walls Out-of-Plane Behaviour. Applied Sciences, 10(23), 8745. https://doi.org/10.3390/app10238745

Gattesco, N., Boem, I., \& Dudine, A. (2015). Diagonal compression tests on masonry walls strengthened with a GFRP mesh reinforced mortar coating. Bulletin of Earthquake Engineering, 13(6), 1703-1726. https://doi.org/10.1007/s10518-014-9684-Z
Günaslan, S. E., Karaşin, A., \& Öncü, M. E. (2014). Properties of FRP materials for strengthening. International Journal of Innovative Science, Engineering \& Technology, 1(9), 656-660.

GVR. (2017). Fiber Reinforced Polymer (FRP) Composites Market Analysis By Fiber Type (Glass, Carbon, Basalt, Aramid), By Application (Automotive, Construction, Electronic, Defense), By Region, And Segment Forecasts, 2018 - 2025. Report ID: GVR-2-68038-006-4.

Hemeda, S. (2018, November). Carbon Fiber Reinforced Polymers (CFRP) for Strengthening and Seismic Retrofitting of Historic Circular Masonry Stone Columns. In International Congress and Exhibition" Sustainable Civil Infrastructures: Innovative Infrastructure Geotechnology" (pp. 114-137). Springer, Cham. International. https://doi.org/10.1007/978-3-030-01932-7_11

Isfeld, A. C., Moradabadi, E., Laefer, D. F., \& Shrive, N. G. (2016). Uncertainty analysis of the effect of grout injection on the deformation of multi-wythe stone masonry walls. Construction and Building Materials, 126, 661-672. https://doi.org/10.1016/j.conbuildmat.2016.09.058

Kalali, A., \& Kabir, M. Z. (2012). Cyclic behavior of perforated masonry walls strengthened with glass fiber reinforced polymers. Scientia Iranica, 19(2), 151-165. https://doi.org/10.1016/j.scient.2012.02.011

Kouris, L. A. S., \& Triantafillou, T. C. (2018). State-ofthe-art on strengthening of masonry structures with textile reinforced mortar (TRM). Construction and Building Materials, 188, 1221-1233. https://doi.org/10.1016/j.conbuildmat.2018.08.039

Kuzik, M. D., Elwi, A. E., \& Cheng, J. R. (2003). Cyclic flexure tests of masonry walls reinforced with glass fiber reinforced polymer sheets. Journal of Composites for Construction, 7(1), 20-30. https://doi.org/10.1061/(ASCE)10900268(2003)7:1(20)

Lee, L. S. (2011). Rehabilitation and service life estimation of bridge superstructures. In Service Life Estimation and Extension of Civil Engineering Structures (pp. 117-142). Woodhead Publishing. https://doi.org/10.1533/9780857090928.1.117

Lei, Z., Qu, J. T., \& Wang, Y. (2014). Strengthening of RCbrick masonry walls with opening using basalt fiber reinforced polymer. In Advanced Materials Research (Vol. 1021, pp. 63-67). Trans Tech Publications Ltd. https://doi.org/10.4028/www.scientific.net/AMR.1 021.63

Giresini, L., Paone, S., \& Sassu, M. (2020a). Integrated cost-analysis approach for seismic and thermal improvement of masonry building façades. Buildings, 10(8), 143. https://doi.org/10.3390/buildings10080143 
Giresini, L., Puppio, M. L., \& Taddei, F. (2020b). Experimental pull-out tests and design indications for strength anchors installed in masonry walls. Materials and Structures, 53(4), 1-16. https://doi.org/10.1617/s11527-020-01536-2

Lizundia, B., Lizundia, B., Longstreth, M., Kren, A., \& Abrams, D. P. (1997). Development of procedures to enhance the performance of rehabilitated URM buildings. US Department of Commerce, National Institute of Standards and Technology.

Mahltig, B., \& Kyosev, Y. (2018). Inorganic and Composite Fibers: Production, Properties and Applications.

Mahmood, H., \& Ingham, J. M. (2011). Diagonal compression testing of FRP-retrofitted unreinforced clay brick masonry wallettes. Journal of Composites for Construction, 15(5), 810-820. https://doi.org/10.1061/(ASCE)CC.19435614.0000209

Marcari, G., Manfredi, G., Prota, A., \& Pecce, M. (2007). In-plane shear performance of masonry panels strengthened with FRP. Composites Part B: Engineering, 38(7-8), 887-901. https://doi.org/10.1016/j.compositesb.2006.11.004

Martelli, A. (2013). The GLIS commitment to seismic prevention continues-First of all, finally, Italian schools are to be protected. 21st Century-Science and Technology, (2), 17-23.

Masuelli, M. A. (2013). Introduction of fibre-reinforced polymers-polymers and composites: concepts, properties and processes. In Fiber reinforced polymersthe technology applied for concrete repair. IntechOpen. https://doi.org/10.5772/3162

Menna, C., Asprone, D., Durante, M., Zinno, A., Balsamo, A., \& Prota, A. (2015). Structural behaviour of masonry panels strengthened with an innovative hemp fibre composite grid. Construction and Building materials, 100, 111-121. https://doi.org/10.1016/j.conbuildmat.2015.09.051

NTC. (2018). Italian building code 'Norme Tecniche per le Costruzioni-NTC18' Ministero delle infrastrutture e dei Trasporti. https://www.gazzettaufficiale.it/eli/gu/2018/02/20/4 2/so/8/sg/pdf.

Mistretta, F., Stochino, F., \& Sassu, M. (2019). Structural and thermal retrofitting of masonry walls: An integrated cost-analysis approach for the Italian context. Building and Environment, 155, 127-136. https://doi.org/10.1016/j.buildenv.2019.03.033

Mouritz, A. P. (2012). Manufacturing of fibre-polymer composite materials. Introduction to Aerospace Materials; Woodhead Publishing: Sawston, UK; Cambridge, UK, 10, 303-337. https://doi.org/10.1533/9780857095152.303
Mustafaraj, E., Yardim, Y., Corradi, M., \& Borri, A. (2020). Polypropylene as a Retrofitting Material for Shear Walls. Materials, 13(11), 2503. https://doi.org/10.3390/ma13112503

Nedwell, P.J. and R. Swamy. 1994. Ferrocement Proceedings of the Fifth international Symposium on Ferrecement. UMIST, Manchester, 6-9 September 1994. London: E \& FN Spon, 1994. 28-30.

Ortega, J., Vasconcelos, G., Rodrigues, H., Correia, M., \& Lourenço, P. B. (2017). Traditional earthquake resistant techniques for vernacular architecture and local seismic cultures: A literature review. Journal of Cultural Heritage, 27, 181-196. https://doi.org/10.1016/j.culher.2017.02.015

Oskouei, A. V., Jafari, A., Bazli, M., \& Ghahri, R. (2018). Effect of different retrofitting techniques on in-plane behavior of masonry wallettes. Construction and Building Materials, 169, 578-590. https://doi.org/10.1016/j.conbuildmat.2018.02.197

Osugi, R., Takagi, H., Liu, K., \& Gennai, Y. (2009, November). Thermal conductivity behavior of natural fiber-reinforced composites. In Proceedings of the Asian pacific conference for materials and mechanics, Yokohama, Japan (pp. 13-16).

Padalu, P. K. V. R., Singh, Y., \& Das, S. (2019). Out-ofplane flexural strengthening of URM wallettes using basalt fibre reinforced polymer composite. Construction and Building Materials, 216, 272-295. https://doi.org/10.1016/j.conbuildmat.2019.04.268

Padalu, P. K. V. R., Singh, Y., \& Das, S. (2020). Cyclic two-way out-of-plane testing of unreinforced masonry walls retrofitted using composite materials. Construction and Building Materials, 238, 117784. https://doi.org/10.1016/j.conbuildmat.2019.117784

Papanicolaou, C., Triantafillou, T., \& Lekka, M. (2011). Externally bonded grids as strengthening and seismic retrofitting materials of masonry panels. Construction and Building Materials, 25(2), 504-514. https://doi.org/10.1016/j.conbuildmat.2010.07.018

Pittau, F., Malighetti, L. E., Iannaccone, G., \& Masera, G. (2017). Prefabrication as large-scale efficient strategy for the energy retrofit of the housing stock: An Italian case study. Procedia engineering, 180, 1160-1169. https://doi.org/10.1016/j.proeng.2017.04.276

Pohoryles, D. A., Maduta, C., Bournas, D. A., \& Kouris, L. A. (2020). Energy performance of existing residential buildings in Europe: A novel approach combining energy with seismic retrofitting. Energy and Buildings, 223, 110024. https://doi.org/10.1016/j.enbuild.2020.110024

Prota, A., Marcari, G., Fabbrocino, G., Manfredi, G., \& Aldea, C. (2006). Experimental in-plane behavior of tuff masonry strengthened with cementitious matrix-grid composites. Journal of Composites for Construction, 10(3), 223-233. https://doi.org/10.1061/(ASCE)10900268(2006)10:3(223) 
Rahman, A., \& Ueda, T. (2016). In-plane shear performance of masonry walls after strengthening by two different FRPs. Journal of composites for construction, 20(5), 04016019. https://doi.org/10.1061/(ASCE)CC.19435614.0000661

Rajak, D. K., Pagar, D. D., Menezes, P. L., \& Linul, E. (2019). Fiber-reinforced polymer composites: Manufacturing, properties and applications. Polymers, 11(10), 1667. https://doi.org/10.3390/polym11101667

Raut, A. N., \& Gomez, C. P. (2016). Thermal and mechanical performance of oil palm fiber reinforced mortar utilizing palm oil fly ash as a complementary binder. Construction and Building Materials, 126, 476-483. https://doi.org/10.1016/j.conbuildmat.2016.09.034

Righetti, L., Edmondson, V., Corradi, M., \& Borri, A. (2016). Fiberglass grids as sustainable reinforcement of historic masonry. Materials, 9(7), 603. https://doi.org/10.3390/ma9070603

Saba, N., Tahir, P. M., \& Jawaid, M. (2014). A review on potentiality of nano filler/natural fiber filled polymer hybrid composites. Polymers, 6(8), 2247-2273. https://doi.org/10.3390/polym6082247

Sakthivel, P. B., \& Jagannathan, A. (2011). Ferrocement construction technology and its applications-A Review.

Saleem, A., Medina, L., Skrifvars, M., \& Berglin, L. (2020). Hybrid Polymer Composites of Bio-Based Bast Fibers with Glass, Carbon and Basalt Fibers for Automotive Applications-A Review. Molecules, 25(21), 4933. https://doi.org/10.3390/molecules25214933

Sassu, M., Giresini, L., Bonannini, E., \& Puppio, M. L. (2016). On the use of vibro-compressed units with bio-natural aggregate. Buildings, 6(3), 40. https://doi.org/10.3390/buildings6030040

Shabdin, M., Attari, N. K., \& Zargaran, M. (2018). Experimental study on seismic behavior of UnReinforced Masonry (URM) brick walls strengthened with shotcrete. Bulletin of Earthquake Engineering, 16(9), 3931-3956. https://doi.org/10.1007/s10518-018-0340-x

Banthia, N. (2019). Advances in sprayed concrete (shotcrete). In Developments in the Formulation and Reinforcement of Concrete (pp. 289-306). Woodhead Publishing. https://doi.org/10.1016/B978-0-08-1026168.00012-5

Shamsuddoha, M., Islam, M. M., Aravinthan, T., Manalo, A., \& Lau, K. T. (2013). Effectiveness of using fibre-reinforced polymer composites for underwater steel pipeline repairs. Composite Structures, $\quad 100, \quad 40-54$. https://doi.org/10.1016/j.compstruct.2012.12.019
Siddiqui, M. Z., Everett, J. W., \& Vieux, B. E. (1996). Landfill siting using geographic information systems: a demonstration. Journal of environmental engineering, 122(6), 515-523. https://doi.org/10.1061/(ASCE)07339372(1996)122:6(515)

Silva, P. F., Yu, P., \& Nanni, A. (2008). Monte Carlo simulation of shear capacity of URM walls retrofitted by polyurea reinforced GFRP grids. Journal of Composites for Construction, 12(4), 405-415. https://doi.org/10.1061/(ASCE)10900268(2008)12:4(405)

Sivaraja, S. S., Thandavamoorthy, T. S., Vijayakumar, S., Mosesaranganathan, S., Rathnasheela, P. T., \& Dasarathy, A. K. (2013). GFRP Strengthening and Applications of Unreinforced Masonry wall (UMW). Procedia Engineering, 54, 428-439. https://doi.org/10.1016/j.proeng.2013.03.038

Smits, J. (2016). Fiber-Reinforced Polymer Bridge Design in the Netherlands: Architectural Challenges toward Innovative, Sustainable and Durable Bridges. Engineering. 2016; 2: 518-527. https://doi.org/10.1016/J.ENG.2016.04.004

Sonnenschein, R., Gajdosova, K., \& Holly, I. (2016). FRP composites and their using in the construction of bridges. Procedia engineering, 161, 477-482. https://doi.org/10.1016/j.proeng.2016.08.665

Srinivasababu, N., Rao, K. M. M., \& Kumar, J. S. (2009). Experimental determination of tensile properties of okra, sisal and banana fiber reinforced polyester composites. Indian Journal of Science and Technology, 2(7), 35-38 https://doi.org/10.17485/ijst/2009/v2i7.8

Stratford, T., Pascale, G., Manfroni, O., \& Bonfiglioli, B. (2004). Shear strengthening masonry panels with sheet glass-fiber reinforced polymer. Journal of Composites for Construction, 8(5), 434-443. https://doi.org/10.1061/(ASCE)10900268(2004)8:5(434)

Tempesta, G. (2018). Seismic retrofit of historical masonry walls by means of natural basalt fiber strips system (BFRP). Pre-modern concepts and innovative materials. In MATEC Web of Conferences (Vol. 242, p. 01014). EDP Sciences. https://doi.org/10.1051/matecconf/201824201014

UN.SDG. (2020). The-Sustainable Development-Goals. https://sdgs.un.org/goals

UNFCCC, V. (2015). Adoption of the Paris agreement. Proposal by the President.

Valenza, A., Fiore, V., Nicolosi, A., Rizzo, G., Scaccianoce, G., \& Di Bella, G. (2015). Effect of sheep wool fibres on thermal-insulation and mechanical properties of cement matrix. Academic Journal of Civil Engineering, 33(2), 40-45. 
Vintzileou, E., \& Tassios, T. P. (1995). Three-leaf stone masonry strengthened by injecting cement grouts. Journal of Structural Engineering, 121(5), 848-856. https://doi.org/10.1061/(ASCE)07339445(1995)121:5(848)

Vintzileou, E., Mouzakis, C., Adami, C. E., \& Karapitta, L. (2015). Seismic behavior of three-leaf stone masonry buildings before and after interventions: Shaking table tests on a two-storey masonry model. Bulletin of Earthquake Engineering, 13(10), 3107-3133. https://doi.org/10.1007/s10518-015-9746-x

Wang, C., Sarhosis, V., \& Nikitas, N. (2018). Strengthening/retrofitting techniques on unreinforced masonry structure/element subjected to seismic loads: A literature review. The Open Construction and Building Technology Journal, 12(1). https://doi.org/10.2174/1874836801812010251

Warnar, J. (1996). Shotcrete in Seismic Repair and Retrofit. Special Publication, 160, 299-314.
Wu, Z., Y. Wu and Md. F.M. Fahmy, 2020, Fundamental behavior of fiber-reinforced polymers and their bonding technique. In book: Structures Strengthened with Bonded Composites (pp.1-85). https://doi.org/10.1016/B978-0-12821088-8.00001-1

Yun, K. K., BAEK, Y. S., HAN, S. Y., \& KIM, Y. G. (2019). Plastic Shrinkage Properties of Natural Fiber Reinforced Shotcrete.

Zhao, J., Cai, G., Cui, L., Si Larbi, A., \& Daniel Tsavdaridis, K. (2017). Deterioration of basic properties of the materials in FRP-strengthening RC structures under ultraviolet exposure. Polymers, 9(9), 402. https://doi.org/10.3390/polym9090402

Zhou, D., Lei, Z., \& Wang, J. (2013). In-plane behavior of seismically damaged masonry walls repaired with external BFRP. Composite Structures, 102, 9-19. https://doi.org/10.1016/j.compstruct.2013.01.031 